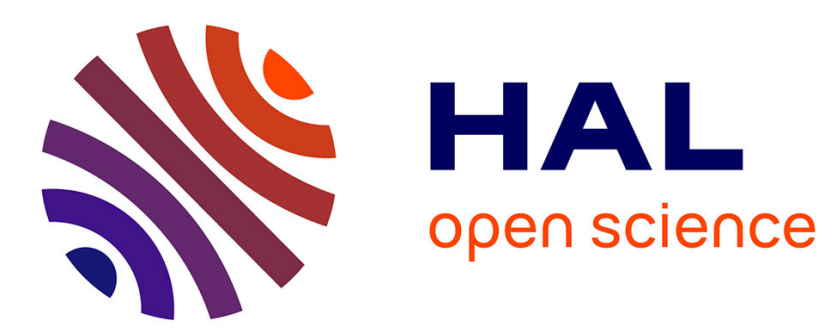

\title{
A robust identification of single crack location and size only based on pulsations of the cracked system Jean-Jacques Sinou
}

\section{To cite this version:}

Jean-Jacques Sinou. A robust identification of single crack location and size only based on pulsations of the cracked system. Structural Engineering and Mechanics, 2007, 25 (6), pp.691-716. hal-00322905

\section{HAL Id: hal-00322905 \\ https://hal.science/hal-00322905}

Submitted on 5 Feb 2013

HAL is a multi-disciplinary open access archive for the deposit and dissemination of scientific research documents, whether they are published or not. The documents may come from teaching and research institutions in France or abroad, or from public or private research centers.
L'archive ouverte pluridisciplinaire HAL, est destinée au dépôt et à la diffusion de documents scientifiques de niveau recherche, publiés ou non, émanant des établissements d'enseignement et de recherche français ou étrangers, des laboratoires publics ou privés. 


\title{
A robust identification of single crack location and size only based on pulsations of the cracked system
}

\author{
Jean-Jacques Sinou \\ Laboratoire de Tribologie et Dynamique des Systèmes UMR-CNRS 5513 \\ Ecole Centrale de Lyon \\ 36 avenue Guy de Collongue \\ 69134 Ecully Cedex, France \\ jean-jacques.sinou@ec-lyon.fr
}

\begin{abstract}
The purpose of the present work is to establish a method for predicting the location and depth of a crack in a circular cross section beam by only considering the frequencies of the cracked beam. An accurate knowledge of the material properties is not required. The crack location and size is identified by finding the point of intersection of pulsation ratio contour lines of lower vertical and horizontal modes. This process is presented and numerically validated in the case of a simply supported beam with various crack locations and sizes. If the beam has structural symmetry, the identification of crack location is performed by adding an off-center placed mass to the simply supported beam. In order to avoid worse diagnostic, it was demonstrated that a robust identification of crack size and location is possible if two tests are undertaken by adding the mass at at the left and then right end of the simply supported beam.

Finally, the pulsation ratio contour lines method is generalized in order to be extended to the case of rectangular cross section beams or more complex structures.
\end{abstract}

Keywords: vibration, crack, identification.

\section{Introduction}

Cracks are a main cause of structural failure and often occurs on structures. In order to avoid the sudden failure of structural components, a crack must be detected in the early state. In recent years, many research studies has been devoted to develop non-destructive techniques for damage identification in structures.

One of the most useful techniques is based on the changes in the modal properties mainly natural frequencies and mode shapes. Even if this approach may be time consuming, the change in modal properties of cracked structures can be useful for easily identification of both crack size and location.

First of all, some researchers demonstrated that the location of a crack may be determined by only using the ratios of the changes in the natural frequencies ( [1-4]). For example, Narkis [5] demonstrated that the only variation of the first two natural frequencies due to the crack is sufficient in order to identify the crack location of a simply supported uniform beam if the crack size is very small. Then, the work of Narkis was continued and developed by Morassi [6] that studied the identification of a single crack based on the knowledge of the damage-induced shifts in a pair of natural frequencies. Moreover, Morassi et al. ( $[7,8])$ proposed very elegant and original approaches to identify localized damage by using the changes in the nodes of mode shapes or by considering not only the measured changes in natural frequencies but also the antiresonant frequencies [9]. One of the most important result of this study was the uniqueness of the damage location for symmetrical beams by considering an appropriate use of frequencies and antiresonances.

Furthermore, Liang et al. [10] developed a method based on measurements of natural frequencies of structures for the detection of crack size and location in a uniform beam under simply supported or cantilever boundary conditions. Cerri and Vestroni [11] proposed to identify structural damage of a beam using measured frequencies by using two different 


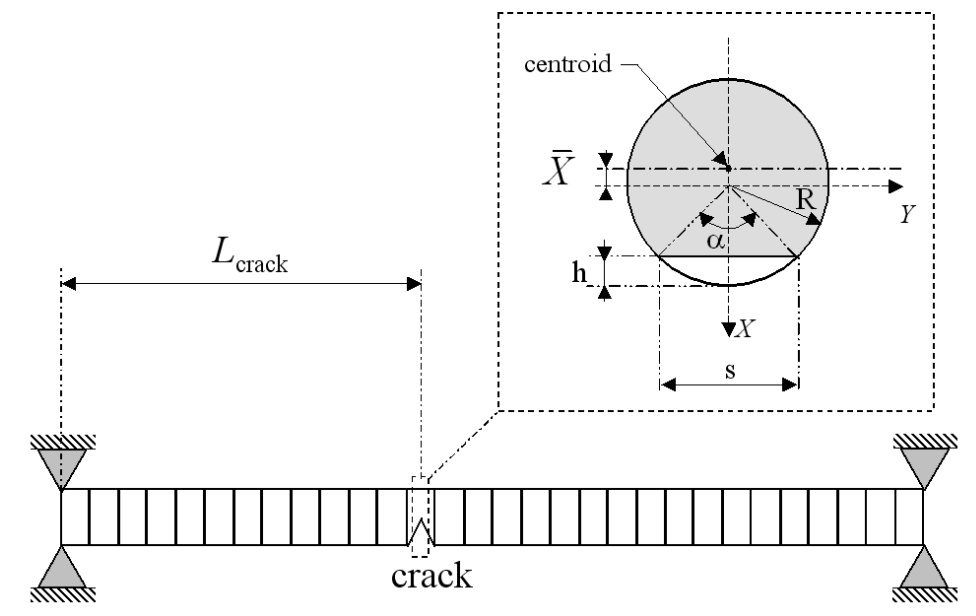

Figure 1: Finite-element model of the beam with the crack cross-section

procedures: the first approach for damage identification is based on the modal equation procedure and the second is based on the frequency comparison between analytical and experimental frequency values. Owolabi et al. [12] considered the damage-induced shifts in the first three natural frequencies and the corresponding amplitudes in order to detect the presence of a crack in beams, and determine its location and size, based on experimental modal analysis results. A similar analytical and experimental approaches were undertaken by Nahvi and Jabbari [13] by considering the normalized frequency in terms of the non-dimensional crack depth and location. Li et al. [14] proposed to identify the crack location and size by finding the point of intersection of three frequency contour lines of the cracked beam under the situation that measured natural frequencies of crack beams are set as input. Hadjileontiadis [15] proposed a new technique based on fractal dimension analysis. The size of the crack is related to the fractal dimension measure, while the location of the crack is determined by the sudden changes in the spatial variation of the cracked beam response. Khiem and Lien [16] formulated a multi-crack detection for beam based on natural frequencies and nonlinear optimization problem. Kim and Stubbs [17] proposed a crack detection model by relating fractional changes in modal energy to changes in natural frequencies due to damage such as cracks or other geometrical changes.

The objective of this work is to extend the frequency contour lines method of crack detection for a circular section beam without using the natural frequencies of uncracked beam (i.e. the change in modal properties between the cracked and uncracked beam are not taken into account) and without needing an accurate knowledge of the Young's modulus and the density. First of all, the circular cross section beam with an open crack is presented. Then, the variations of the first three frequency ratios of the vertical and horizontal modes as a function of non-dimensional crack depth ratio, the crack location and some changes of the material properties (Young modulus and density) are undertaken.

In a second part, the identification of crack size and location is performed by considering only the damage-induced shifts in the first three change ratios of the vertical and horizontal natural frequencies of the cracked circular beam. Moreover, in order to avoid the non-uniqueness of the damage location problem due to the structural symmetry of beams and worse diagnostic, the process of adding an off-center mass to the simply supported beam is investigated. Finally, the pulsation ratio contour lines method is generalized in order to be extended to the case of rectangular cross section beams or more complex structures.

\section{The model of the simply supported cracked beam}

In this paper, a circular cross section beam, $1 \mathrm{~m}$ in length with a diameter of $0.1 \mathrm{~m}$, is modellled using 31 Timoshenko beam finite elements ( $[18,19])$ with four degrees of freedoms in each node as shown in Figure 1. The beam is assumed to be simply supported at each end. The presence of a transverse crack in beams introduces considerable local 
flexibility due to strain energy concentration in the vicinity of the crack tip under load. This highly localized effect does not influence the stiffness of the segment of the beam away from the crack cross section. To locally represent the stiffness properties of the crack cross section in an otherwise uncracked beam, it is necessary to incorporate flexibility due to the presence of the transverse crack. We refer the interested reader to [20,21] for comprehensive literature survey of various crack modeling techniques.

Mayes and Davies ( $[22,23])$ proposed to theoretically model a transverse crack by reducing the second moment of area of the element at the location of the crack by $\Delta I$. In [24], they indicated that the change in the $m^{\text {th }}$ natural frequency of a system containing a crack may be defined by

$$
\Delta \omega_{m}^{2}=-g\left(\frac{d^{2} u_{m}}{d x^{2}}\right)_{x=s_{c}}
$$

where $g$ is a function of crack and beam geometry and $u_{m}$ defines the $m^{\text {th }}$ mode shape of the beam. $s_{c}$ corresponds to the location of the crack on the beam. Extending their study and using dimensional analysis to describe the stress concentration factor at the crack front, they obtained the following expression [22]

$$
\Delta \omega_{m}^{2}=-4 \frac{E I^{2}}{\pi R^{3}}\left(1-\nu^{2}\right) F(\mu)\left(\frac{d^{2} u_{m}}{d x^{2}}\right)_{x=s_{c}}
$$

where $I, R, \mu, E$ and $\nu$ are the second moment of area, the shaft radius, the non-dimensional crack depth, the Young's modulus and the Poisson's ratio, respectively. $F(\mu)$ is the non-linear compliance function varied with the non-dimensional crack depth $\mu$ and is independent of all the other parameters. Mayes and Davies ( [22,23]) proposed to obtain the evolution of $F(\mu)$ from a series of experiments with chordal cracks. This compliance function was then used by Lees et al [25] to study the dynamic behaviour of a shaft with a crack accounting opening and closing of crack due to the shaft self weight for different orientations of the shaft.

Then using the second derivatives of the deflection curves, the bending moment $M_{0}$ for the original system is given by

$$
M_{0}(s)=E I_{0}(s)\left(\frac{d^{2} y}{d x^{2}}\right)_{x=s}
$$

where $y$ and $s$ define the shaft displacement of the beam and the axial position.

The bending moment $M$ for the perturbed system due to the presence of a crack is given by

$$
M(s)=M_{0}(s)-\Delta M(s)=E\left(I_{0}(s)-\Delta I(s)\right)\left(\frac{d^{2} y}{d x^{2}}\right)_{x=s} .
$$

Moreover, assuming that the deflection curve is unchanged, the bending moment $M_{0}$ of the original system and the bending moment $M$ of the cracked system are defined by

$$
M_{0}(s)=\omega_{0}^{2} \int_{0}^{s}(s-z) m(z) y(z) d z
$$

and

$$
\Delta M(s)=\Delta \omega_{0}^{2} \int_{0}^{s}(s-z) m(z) y(z) d z
$$

where $m(z)$ corresponds to the mass/unit length at the location $z$ on the beam.

Using Equations 3-6 and Rayleigh's approach, Mayes and Davies [22] demonstrated the relation

$$
\Delta \omega^{2}=E\left(\frac{d^{2} y}{d x^{2}}\right)_{x=s}\left(\frac{\Delta I}{1-\frac{\Delta I}{I_{0}}}\right)\left(1-\frac{\Delta \omega^{2}}{\omega_{0}^{2}}\right) .
$$

Then, they proposed to compare Equations 2 and 7 and to only consider the first order changes in $\Delta \omega^{2}$ and they obtained after calculation

$$
\frac{\Delta I}{1-\frac{\Delta I}{I_{0}}}=-4 \frac{I_{0}^{2}}{\pi l R^{3}}\left(1-\nu^{2}\right) F(\mu) .
$$


For a circular beam, this relation becomes

$$
\frac{\Delta I}{I_{0}}=\frac{\frac{R}{l}\left(1-\nu^{2}\right) F(\mu)}{1+\frac{R}{l}\left(1-\nu^{2}\right) F(\mu)}
$$

where $I_{0}, R, l$, and $\nu$ are the second moment of area, the shaft radius, the length of the section and the Poisson's ratio, respectively. $\mu$ is the non-dimensional crack depth and is given by

$$
\mu=\frac{h}{R}
$$

where $h$ defines the crack depth of the shaft, as illustrated in Figure 1. At the crack location, the stiffness matrix $\mathbf{K}_{\text {crack }}$ due to the transversal crack is defined as (to the principal axes of the crack front)

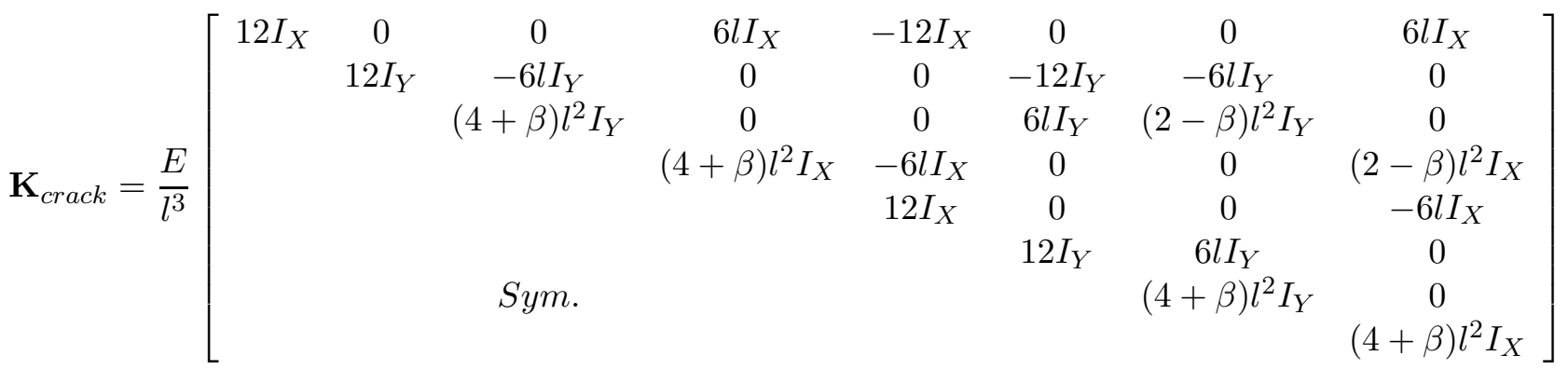

where $\beta$ is the shear modulus of the beam.

The moments of inertia about the parallel centroidal axes, $I_{X}$ and $I_{Y}$, are given by [26]

$$
\begin{gathered}
I_{X}=\tilde{I}_{X} \\
I_{Y}=\tilde{I}_{Y}-A \bar{X}^{2}
\end{gathered}
$$

where $A$ and $\bar{X}^{2}$ define the uncracked area of the cross-section and the distance from the axis $X$ to the centroid of the cross section

$$
\begin{gathered}
A=R^{2}\left((1-\mu) \gamma+\frac{\alpha}{2}\right) \\
\bar{X}=\frac{2}{3 A} R^{3} \gamma^{3}
\end{gathered}
$$

and the asymmetric area moments of inertia $\tilde{I}_{X}$ and $\tilde{I}_{Y}$ about the $\mathrm{X}$ and Y-axes are defined as

$$
\tilde{I}_{X}=\iint_{A} Y^{2} d A=\frac{R^{4}}{4}\left((1-\mu)\left(1-4 \mu+2 \mu^{2}\right) \gamma+\frac{\alpha}{2}\right)
$$

and

$$
\tilde{I}_{Y}=\iint_{A} X^{2} d A=\frac{\pi R^{4}}{4}+R^{4}\left(\frac{2}{3}(1-\mu) \gamma^{3}+\frac{1}{4}(1-\mu)\left(1-4 \mu+2 \mu^{2}\right) \gamma+\sin ^{-1}(\gamma)\right) .
$$

$R$ is the shaft radius, $\mu$ is the non-dimensional crack depth, and $\gamma=\sqrt{2 \mu-\mu^{2}}$ for convenience. $\alpha$ is the crack angle (as shown in Figure 1) and is defined as

$$
\alpha=2 \cos ^{-1}(1-\mu) .
$$

Finally, the equations of the simply supported cracked beam motion can be written as

$$
\mathbf{M} \ddot{\mathbf{X}}+\mathbf{K X}=\mathbf{0}
$$

where overdots indicate differentiation with respect to time. $\mathbf{M}$ and $\mathbf{K}$ are the global mass and stiffness matrices, respectively. $\mathbf{K}$ contains the stiffness reduction $\mathbf{K}_{\text {crack }}$ at the crack location.

The frequencies can be found by solving generalized eigenvalues of

$$
\operatorname{det}\left(-\omega^{2} \mathbf{M}+\mathbf{K}\right)=\mathbf{0} .
$$




\begin{tabular}{cccccccc}
$E(\mathrm{GPa})$ & $\mu$ & $\omega_{1}^{\text {cracked }}$ & $\omega_{2}^{\text {cracked }}$ & $\omega_{3}^{\text {cracked }}$ & $\omega_{4}^{\text {cracked }}$ & $\omega_{5}^{\text {cracked }}$ & $\omega_{6}^{\text {cracked }}$ \\
\hline \multirow{2}{*}{190} & 0 & 1217.8 & 1217.8 & 4871.1 & 4871.1 & 10960 & 10960 \\
& 0.5 & 1173.6 & 1182.2 & 4868.5 & 4869.0 & 10596 & 10663 \\
& 1 & 974.6 & 1166 & 4856 & 4868.1 & 9385.6 & 10537 \\
195 & 0 & 1233.7 & 1233.7 & 4934.8 & 4934.8 & 11103 & 11103 \\
& 0.5 & 1189 & 1197.7 & 4932.2 & 4932.7 & 10734 & 10803 \\
& 1 & 987.4 & 1181.2 & 4919.4 & 4931.7 & 9508.3 & 10675 \\
200 & 0 & 1249.4 & 1249.4 & 4997.7 & 4997.7 & 11245 & 11245 \\
& 0.5 & 1204.1 & 1212.9 & 4995 & 4995.5 & 10871 & 10940 \\
& 1 & 1000 & 1196.3 & 4982.1 & 4994.5 & 9629.4 & 10811 \\
205 & 0 & 1264.9 & 1264.9 & 5059.7 & 5059.7 & 11384 & 11384 \\
& 0.5 & 1219.1 & 1228 & 5057.1 & 5057.6 & 11006 & 11076 \\
& 1 & 1012.4 & 1211.2 & 5044 & 5056.6 & 9749.1 & 10945 \\
& 0 & 1280.3 & 1280.3 & 5121.1 & 5121.1 & 11522 & 11522 \\
& 0.5 & 1233.8 & 1242.9 & 5118.4 & 5118.9 & 11139 & 11211 \\
& 1 & 1024.7 & 1225.8 & 5105.2 & 5117.9 & 9867.2 & 11078 \\
\hline
\end{tabular}

Table 1: Variation of $\omega_{i}^{\text {cracked }}$ (in rad.s $\mathrm{s}^{-1}$ ) with the variation of the Young's modulus $E$ and non-dimensional crack depth $\mu$ (with $\rho=7800 \mathrm{~kg} \cdot \mathrm{m}^{-3}$ and $L_{\text {crack }}=0.4833 \mathrm{~m}$ )

\section{Numerical studies}

\subsection{Effects of crack}

Generally, a crack induces changes in the structures' stiffness, and also induces frequency reductions of the structure ( $[1-12,14,17])$. These well-known effects of cracks on the natural frequencies are illustrated in Figures 2 that show the change in pulsations $\omega_{i}^{\text {cracked }}(i=1, \ldots, 6)$ for the simply supported beam with the variations of the nondimensional crack depth $\mu$ and the crack location $L_{\text {crack}}$. For the sake of clarity, it may be noted that the odd-order modes and even-order modes of the cracked beam correspond to bending modes in the vertical and horizontal planes. The largest crack considered in this study corresponds to the case of half the area of the cross-section is missing due to the transverse crack (i.e. $\mu=1$ ). It clearly appears that both crack location and depth have influences on the pulsations of the supported cracked beam. Then, the highest changes occur in the vertical modes $\left(\omega_{1}^{\text {cracked }}, \omega_{3}^{\text {cracked }}\right.$ and $\omega_{5}^{\text {cracked }}$ ) due to the orientation of the crack and the beam self-weight. Basically, the pulsations are unchanged when the crack is situated at one node of the associated mode (i.e. at the middle of the beam for second vertical and horizontal modes, and at one-third and two-third of the beam for third vertical and horizontal modes). Moreover, the change in pulsations increases when the non-dimensional crack depth increases. Then, Tables 1 and 2 indicate the variation of $\omega_{i}^{\text {cracked }}(i=1, \ldots, 6)$ for the simply supported beam with the variation of the Young's modulus $E$ and the density $\rho$. It appears that the material properties (i.e. Young's modulus $E$ and the density $\rho$ ) clearly affect the natural frequencies of the cracked beam. These results are in perfect coherence with the analytical solution of a simply supported beam given in Appendix A. The third and fourth natural pulsations $\omega_{3}^{\text {cracked }}$ and $\omega_{4}^{\text {cracked }}$ are almost unaffected. This is due to the fact that the crack is located at the center of the beam, near the node of those two modes of vibration.

Therefore, an accurate knowledge and estimation of the material properties is needed.

This work was investigated by Li et al. [14]. They proposed to identify the crack size and position based on the calculated first three natural cracked frequencies. Due to the fact that the changes in the natural frequencies of a cracked beam are affected by the crack location and the crack size, a particular frequency can correspond to different crack locations and crack sizes. The intersection of the three contour lines of the first three natural cracked frequencies indicates the possible crack position and crack size. In this case, the evaluation of the cracked natural frequencies 


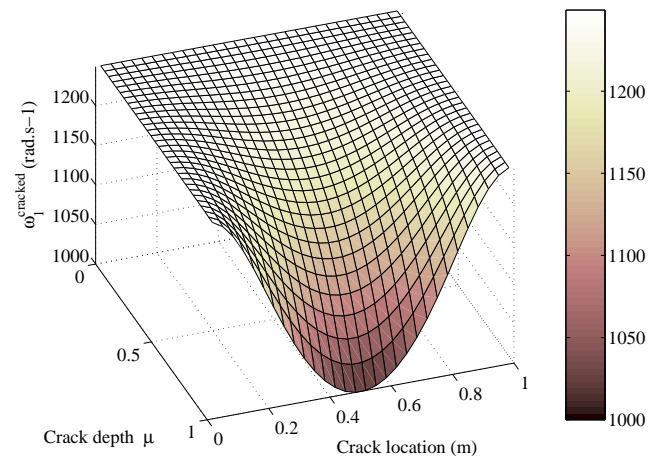

(a) $\omega_{1}^{\text {cracked }}$

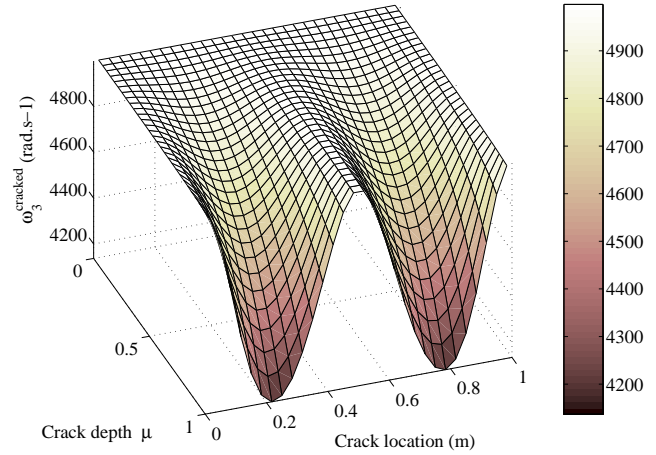

(c) $\omega_{3}^{\text {cracked }}$

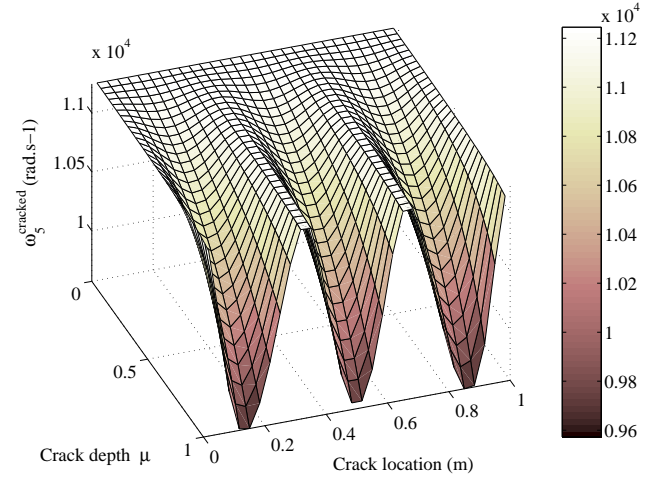

(e) $\omega_{5}^{\text {cracked }}$

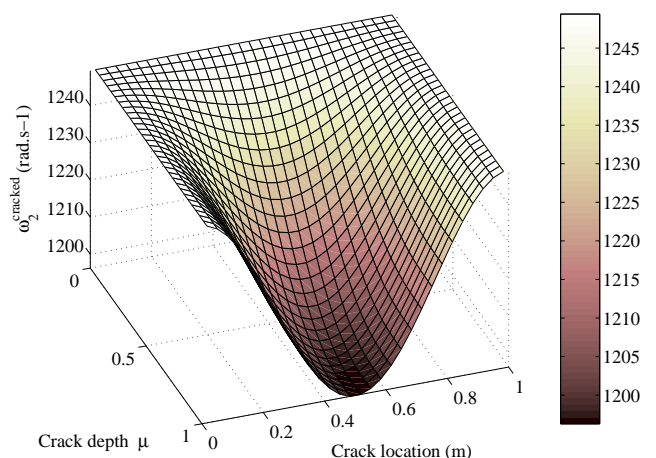

(b) $\omega_{2}^{\text {cracked }}$

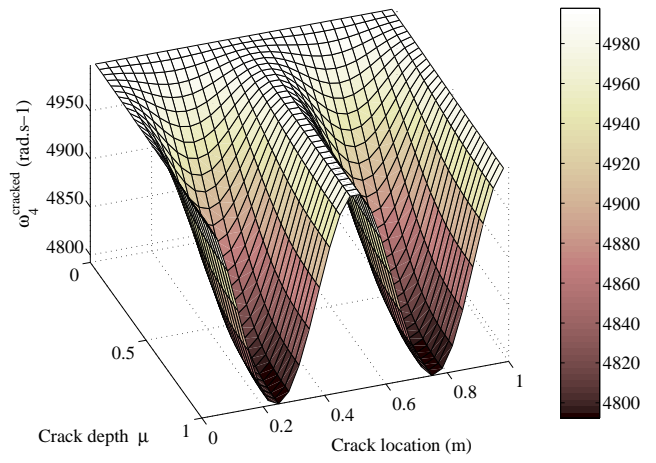

(d) $\omega_{4}^{\text {cracked }}$

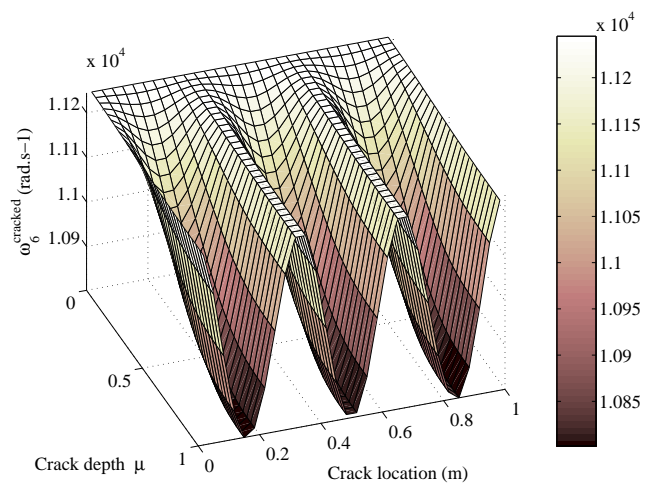

(f) $\omega_{6}^{\text {cracked }}$

Figure 2: Change in pulsations $\omega_{i}^{\text {cracked }}(i=1, \ldots, 6)$ for the simply supported beam with the variation of the non-dimensional crack depth $\mu$ and the crack location $L_{\text {crack }}$ 


\begin{tabular}{cccccccc}
$\rho\left(\mathrm{kg} . \mathrm{m}^{-3}\right)$ & $\mu$ & $\omega_{1}^{\text {cracked }}$ & $\omega_{2}^{\text {cracked }}$ & $\omega_{3}^{\text {cracked }}$ & $\omega_{4}^{\text {cracked }}$ & $\omega_{5}^{\text {cracked }}$ & $\omega_{6}^{\text {cracked }}$ \\
\hline 7600 & 0 & 1265.7 & 1265.7 & 5063 & 5063 & 11392 & 11392 \\
& 0.5 & 1219.8 & 1228.8 & 5060.3 & 5060.8 & 11013 & 11083 \\
7700 & 1 & 1013 & 1211.9 & 5047.2 & 5059.8 & 9755.3 & 10952 \\
& 0 & 1257.5 & 1257.5 & 5030 & 5030 & 11318 & 11318 \\
& 0.5 & 1211.9 & 1220.8 & 5027.3 & 5027.9 & 10941 & 11011 \\
7800 & 1 & 1006.4 & 1204.0 & 5014.4 & 5026.9 & 9691.8 & 10881 \\
& 0 & 1249.4 & 1249.4 & 4997.7 & 4997.7 & 11245 & 11245 \\
7900 & 0.5 & 1204.1 & 1212.9 & 4995 & 4995.5 & 10871 & 10940 \\
& 1 & 1000 & 1196.3 & 4982.1 & 4994.5 & 9629.4 & 10811 \\
& 0.5 & 1241.5 & 1241.5 & 4965.9 & 4965.9 & 11173 & 11173 \\
8000 & 1 & 1196.5 & 1205.2 & 4963.3 & 4963.8 & 10802 & 10871 \\
& 0 & 993.6 & 1188.7 & 4950.5 & 4962.8 & 9568.3 & 10742 \\
& 0.5 & 1233.7 & 1233.7 & 4934.8 & 4934.8 & 11103 & 11103 \\
& 1 & 1189 & 1197.7 & 4932.2 & 4932.7 & 10734 & 10803 \\
& 9 & 987.4 & 1181.2 & 4919.4 & 4931.7 & 9508.3 & 10675 \\
\hline
\end{tabular}

Table 2: Variation of $\omega_{i}^{\text {cracked }}$ (in rad.s ${ }^{-1}$ ) with the variation of the density $\rho$ and non-dimensional crack depth $\mu$ (with $E=200 G P a$ and $L_{\text {crack }}=0.4833 m$ )

need to be carefully undertaken and require the knowledge of the material properties (the Young's modulus $E$ and the density $\rho$ ). So, Li et al. decided to determine a corrected value of Young's modulus due to the fact that quoted values of Young's modulus are not sufficiently accurate for a correct detection of crack size and location. This correction of the Young's modulus was overcome by an iterative approach, which uses the uncracked natural frequencies of the beams. It may be noted that a bad estimation of the corrected Young's modulus may induced a worse identification of the crack size and position. This last observation may explain the fact when the three curves do not meet exactly, the centroid of the three pairs of intersections is taken as the crack position and crack size ( $[14,27])$.

Some investigators $([12,13,28])$ have given a method similar to the above, but they consider the normalized natural frequencies that are defined as the ratio of cracked beam natural frequency to the uncracked beam natural frequency. This process has the advantage to avoid the determination of an accurate Young's modulus. However, the natural frequencies of the uncracked beam are needed. Another equivalent approach may be to compare the pulsations of the cracked and uncracked systems by defining the percentage change in natural frequencies $\% C_{i}$ [26]

$$
\% C_{i}=100 \times \frac{\omega_{i}^{\text {uncracked }}-\omega_{i}^{\text {cracked }}}{\omega_{i}^{\text {uncracked }}}
$$

where $\omega_{i}^{\text {uncracked }}$ and $\omega_{i}^{\text {cracked }}$ define the $i^{\text {th }}$-pulsation of the uncracked and cracked beam. In these cases, the material properties (i.e. the Young's modulus $E$ and the density $\rho$ ) do not affect these normalized frequencies or the percentage change in natural frequencies $\% C_{i}$. Tables 3 illustrates the evolution of $\% C_{i}(i=1, \ldots, 6)$ with the variation of the crack position $L_{\text {crack }}$ and the non-dimensional crack depth $\mu$. In order to identify the crack depth and location, the frequency contour method [28] that has been previously explained can be achieved by using the lower order normalized frequencies. One of the most important advantages is that the material properties have not to be corrected. However, the uncracked frequencies of the beam need to be known. So, in order to avoid the knowledge of the uncracked frequencies of the beam and the determination of an accurate corrected value of Young's modulus, an alternative approach will be presented. It may be noted that the correct estimation of the Young modulus and linear mass density does not represent a very strong difficulty. However, it may be observed that avoiding the determination of these two physical parameters for the identification of the crack size and location may be interesting in order to obtain a robust damage identification and to save experimental time. 


\begin{tabular}{cccccccc}
\hline & & & & & & & \\
$\mu$ & $L_{\text {crack }}(m)$ & $C_{1}$ & $\% C_{2}$ & $\% C_{3}$ & $\% C_{4}$ & $\% C_{5}$ & $\% C_{6}$ \\
\hline 0.2 & 0.15 & -0.184 & -0.18 & -0.58 & -0.57 & -0.84 & -0.83 \\
& 0.3167 & -0.62 & -0.61 & -0.72 & -0.71 & -0.03 & -0.03 \\
& 0.483 & -0.88 & -0.86 & -0.01 & -0.01 & -0.84 & -0.83 \\
0.4 & 0.15 & -0.53 & -0.47 & -1.66 & -1.49 & -2.36 & -2.12 \\
& 0.3167 & -1.78 & -1.60 & -2.02 & -1.82 & -0.08 & -0.07 \\
& 0.483 & -2.50 & -2.24 & -0.04 & -0.03 & -2.33 & -2.10 \\
0.6 & 0.15 & -1.13 & -0.76 & -3.45 & -2.35 & -4.67 & -3.27 \\
& 0.3167 & -3.69 & -2.51 & -4.02 & -2.81 & -0.16 & -0.11 \\
& 0.483 & -5.10 & -3.50 & -0.07 & -0.05 & -4.57 & -3.21 \\
0.8 & 0.15 & -2.35 & -0.91 & -6.89 & -2.79 & -8.54 & -3.85 \\
& 0.3167 & -7.37 & -2.99 & -7.42 & -3.31 & -0.31 & -0.13 \\
& 0.483 & -9.92 & -4.15 & -0.15 & -0.06 & -8.25 & -3.77 \\
1 & 0.15 & -5.48 & -0.93 & -14.41 & -2.87 & -14.87 & -3.94 \\
& 0.3167 & -15.58 & -3.07 & -13.41 & -3.39 & -0.6 & -0.13 \\
& 0.483 & -19.97 & -4.25 & -0.31 & -0.06 & -14.37 & -3.86 \\
\hline
\end{tabular}

Table 3: Variation of $\% C_{i}$ with the variation of the crack position $L_{\text {crack }}$ and non-dimensional crack depth $\mu$

\subsection{Robust identification technique only based on the pulsation ratios of the cracked beam}

The proposed process is based on the fact that the pulsations associated with the vertical (first, third and fifth pulsations) and horizontal (second, fourth, and sixth pulsations) modes are equal in the case of an uncracked beam, but are different for the cracked beam due to the presence of the crack (as illustrated in Figures 2). Due to the beam selfheight, the most important changes in the pulsations occur in the vertical mode if the orientation of the crack front is to the principal axes, as shown in Figure 1. So, the difference between the pulsations of the vertical and horizontal modes is only due to the size and location of the crack.

Moreover, the expression of the stiffness matrix $\mathbf{K}_{\text {crack }}$ due to the transversal crack (Equation 11) indicates that the material properties (i.e. the Young modulus $E$ and the density $\rho$ ) do not influence the changes in the pulsation ratios of the vertical and horizontal modes.

Therefore, in order to detect the crack size and location, the ratio change $\% \Delta_{i}^{\text {cracked }}$ in the pulsations with the vertical and horizontal modes of the cracked beam is defined as follows:

$$
\% \Delta_{i}^{\text {cracked }}=100 \times \frac{\omega_{2 i-1}^{\text {cracked }}-\omega_{2 i}^{\text {cracked }}}{\omega_{2 i-1}^{\text {cracked }}} .
$$

This percentage change is totally independent of the material properties and needs only the knowledge of the pulsations of the cracked beam.

Figures 3 illustrate the fourth lower terms of the percentage ratio changes $\% \Delta_{i}^{\text {cracked }}$ (for $i=1, \ldots, 4$ ). It may be observed that these changes are significant and indicate the influences of both the non-dimensional crack depth $\mu$ and the crack location $L_{\text {crack }}$. Even if the Young's modulus is uncertain, each surface of Figures 3 is unchanged due to the fact that the $\% \Delta_{i}^{\text {cracked }}$ can be represented by a function that is dependent on the non-dimensional crack depth, the crack location and the two corresponding modes $2 i-1$ and $2 i$. These process is very interesting due to the fact that only the cracked pulsations are considered for the determination of $\% \Delta_{i}^{\text {cracked }}$. The pulsations of the simply supported uncracked beam are not used. Thereby, the identification of crack size and location for a circular section beam can be undertaken by extending the frequency contour lines method proposed by Swamidas et al. $([12,28])$. However, the process proposed in this study does not require the knowledge of the natural frequencies of the uncracked beam. This approach is based on the fact that a contour line which has the same ratio changes $\% \Delta_{i}^{\text {cracked }}$ resulting in a combination of different crack location and crack depths can be plotted as a curve with crack location and crack depth as its 


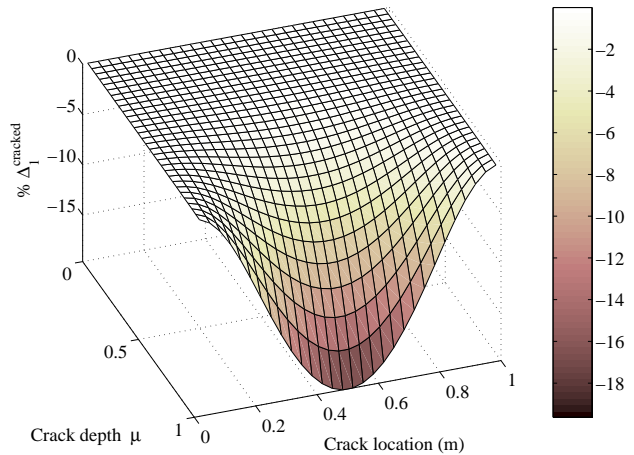

(a) $\% \Delta_{1}^{\text {cracked }}$

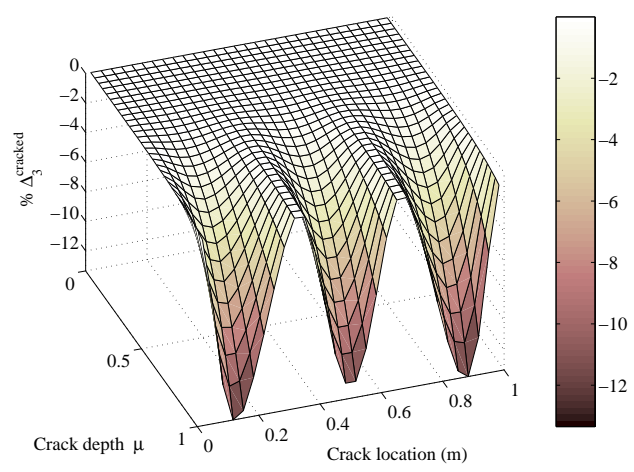

(c) $\% \Delta_{3}^{\text {cracked }}$

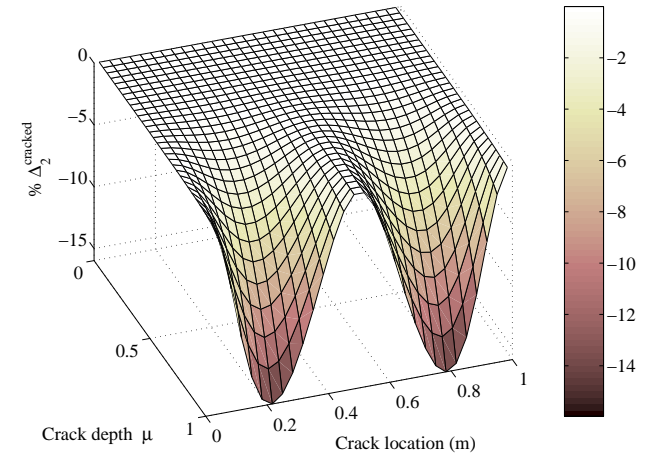

(b) $\% \Delta_{2}^{\text {cracked }}$

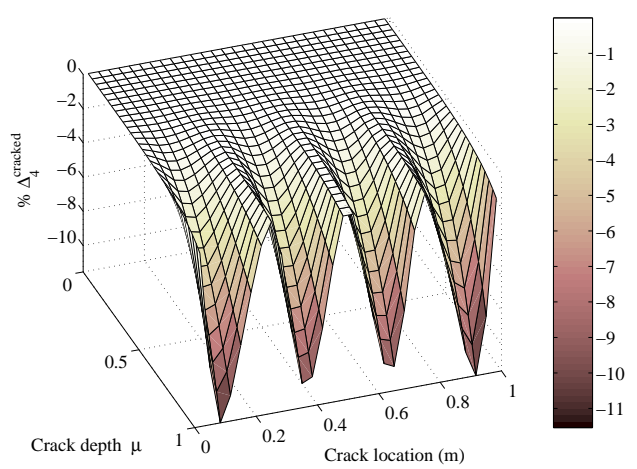

(d) $\% \Delta_{4}^{\text {cracked }}$

Figure 3: Evolution of $\% \Delta_{i}^{\text {cracked }}$ with the variation of the non-dimensional crack depth $\mu$ and the crack location $L_{\text {crack }}$ 


\begin{tabular}{cccccc} 
Case & $\mu$ & $L_{\text {crack }}$ & $\% \Delta_{1}^{\text {cracked }}$ & $\% \Delta_{2}^{\text {cracked }}$ & $\% \Delta_{3}^{\text {cracked }}$ \\
\hline case (a) & 0.1 & 0.283 & $-3 \mathrm{e}-4$ & $-5 \mathrm{e}-4$ & $-1 \mathrm{e}-4$ \\
case (b) & 0.8 & 0.783 & -2.77 & -5.69 & -3.47 \\
case (c) & 0.5 & 0.517 & -0.73 & -0.01 & -0.64 \\
case (d) & 0.4 & 0.183 & -0.01 & $-1 \mathrm{e}-3$ & $-9 \mathrm{e}-3$ \\
case (e) & 0.65 & 0.817 & -0.78 & -2.02 & -1.91 \\
case (f) & 0.4 & 0.183 & -0.08 & -0.22 & -0.23 \\
\hline
\end{tabular}

Table 4: Values of $\% \Delta_{i}^{\text {cracked }}$ for each case with the simply supported beam

axes. Then, the intersection of the contour lines $\% \Delta_{i}^{\text {cracked }}$ for the three lower modes (for $i=1, \ldots, 3$ ) indicates the position and size of the crack. It may be noted that a minimum of three contour lines $\% \Delta_{i}^{\text {cracked }}$ is required in order to identify the crack location and size. Effectively, if the crack is situated at the node of the $i^{\text {th }}$ vertical and horizontal modes, $\omega_{2 i-1}^{\text {cracked }}$ and $\omega_{2 i}^{\text {cracked }}$ remain almost unchanged (see for example [12], [28] and [2]). Thereby, the associated ratio change $\Delta_{i}^{\text {cracked }}$ is equal to zero and the identification is not possible. So, measuring the first six cracked natural pulsations is sufficient to determine the crack location, and the crack depth for a circular cross section beam. For illustrative purposes, Figures 4 show the intersection of the three contour lines of $\% \Delta_{i}^{\text {cracked }}$ (with $i=1, \ldots, 3$ ) for six particular crack cases. Table 4 indicates the values of $\% \Delta_{i}^{\text {cracked }}$ of the pulsation ratio changes contour lines. For each case, it clearly appears that the three contour lines give two intersections that correspond to one crack size but two possible crack locations. Effectively, due to the structural symmetry of the beam, the identification of the crack location is not unique. In order to avoid the non-uniqueness of the damage location problem, the identification of crack location is performed by adding an off-center placed mass to the simply supported beam at $L_{\text {mass }}=0.167 \mathrm{~m}$ from the left end, as illustrated in Figure 5. This added off-center mass changes the values of $\% \Delta_{i}^{\text {cracked }}$. Moreover, the previous symmetry of $\% \Delta_{i}^{\text {cracked }}$ (for the simply supported beam) with the crack location does not exist, as shown in Figures 6. Therefore, the identification of the crack size and location can be undertaken by considering the simply supported beam with the off-center mass. As previously done, measuring the first six cracked natural pulsations of the cracked beam with the off-center mass is sufficient to determine the crack location and the crack depth. Results are given in Figures 7 for the six previous crack cases. Tables 5 indicates the values of $\% \Delta_{i}^{\text {cracked }}$ of the pulsation ratio changes contour lines for the simply supported beam with the added mass at $L_{\text {mass }}=0.167 \mathrm{~m}$. It may be observed that the intersection of the three contour lines $\% \Delta_{i}^{\text {cracked }}$ is unique for the six cases. So, adding an off-center mass enables us to identify the crack size and location. However, it appears that the effect of the off-center mass is not sufficient in all cases. Effectively, it is not very clear and evident that the three contour lines have only one intersection for each case. There may exist a little zone defined by the three intersections for two contour lines and the associated centroid of the three pairs of intersections may be taken as the crack position and crack size (see for examples Figure 7 (a) at $\mu=0.12$ and $L_{\text {crack }}=0.55 \mathrm{~m}$, Figure 7(b) at $\mu=0.69$ and $L_{\text {crack }}=0.19 \mathrm{~m}$, and Figure 7(c) at $\mu=0.5$ and $L_{\text {crack }}=0.3 \mathrm{~m}$ ). This may induced misunderstanding in the case of experimental crack identification where the values of $\% \Delta_{i}^{\text {cracked }}$ can be altered. In order to avoid this problem, we propose to realize two tests for the crack size and location identification by adding an off-center mass at each end of the simply supported beam for each case ( $L_{\text {mass }}=0.167 \mathrm{~m}$ for the first case, and $L_{\text {mass }}=0.833 \mathrm{~m}$ for the second case).

Figures 8 illustrate this process. Table 6 indicates the values of $\% \Delta_{i}^{\text {cracked }}$ of the pulsation ratio changes contour lines for the simply supported beam with the added mass at $L_{\text {mass }}=0.833 \mathrm{~m}$.

As indicated in Figure 7(a), the added mass on the left of the simply supported beam indicates only one intersection of the three contour lines (for $\mu=0.1$ and $L_{\text {crack }}=0.283$ ). However, a centroid located at $\mu=0.12$ and $L_{\text {crack }}=0.55$ may induced worse diagnostic. Now, the added mass on the right of the simply supported beam indicates only one intersection of the three contour lines and a centroid is now located at $\mu=0.1$ and $L_{\text {crack }}=0.78$ (see Figure 8(a)). Thereby, no confusion may be done: we have two centroids for each case but they are not at the same crack size and location and an unique intersection of the three contour lines is obtained at $\mu=0.1$ and $L_{\text {crack }}=0.283$.

Moreover, this process appears to be very effective and robust. For example, Figure 7(b) may induced worse diagnos- 


\begin{tabular}{cccc} 
Case & $\% \Delta_{1}^{\text {cracked }}$ & $\% \Delta_{2}^{\text {cracked }}$ & $\% \Delta_{3}^{\text {cracked }}$ \\
\hline (a) & $-4 \mathrm{e}-4$ & $-4 \mathrm{e}-4$ & $-5 \mathrm{e}-6$ \\
(b) & -2.42 & -4.80 & -4.12 \\
(c) & -0.69 & -0.07 & -0.47 \\
(d) & -0.01 & $-3 \mathrm{e}-3$ & $-5 \mathrm{e}-3$ \\
(e) & -0.67 & -1.62 & -2.02 \\
(f) & -0.12 & -0.36 & -0.20 \\
\hline
\end{tabular}

Table 5: Values of $\% \Delta_{i}^{\text {cracked }}$ for each case with the simply supported beam and the left added mass

\begin{tabular}{cccc}
\hline & & & \\
Case & $\% \Delta_{1}^{\text {cracked }}$ & $\% \Delta_{2}^{\text {cracked }}$ & $\% \Delta_{3}^{\text {cracked }}$ \\
\hline (a) & $-3 \mathrm{e}-4$ & $-4 \mathrm{e}-4$ & $-2 \mathrm{e}-4$ \\
(b) & -3.72 & -6.77 & -1.89 \\
(c) & -0.70 & -0.01 & -0.59 \\
(d) & -0.01 & $-8 \mathrm{e}-5$ & -0.01 \\
(e) & -1.17 & -3.13 & -1.62 \\
(f) & -0.07 & -0.18 & -0.24 \\
\hline
\end{tabular}

Table 6: Values of $\% \Delta_{i}^{\text {cracked }}$ for each case with the simply supported beam and the right added mass

tic due to the fact that two intersections (in fact one perfect intersection and one centroid) are detected (at $\mu=0.8$ and $L_{\text {crack }}=0.783 \mathrm{~m}$ and $\mu=0.69$ and $L_{\text {crack }}=0.19 \mathrm{~m}$ ). Therefore, not only the crack location but also the crack size can be badly identified. Then, considering Figure 8(b), only one intersection is detected at $\mu=0.8$ and $L_{\text {crack }}=0.783 \mathrm{~m}$, corresponding to the crack size and location.

Finally, it may be mentioned that the simply supported beam (without added off-center mass) indicates a first estimation of the crack size and location (in fact two intersection due to the structural symmetry). So, the first detection done by using the simply supported beam can be used to check the robust identification process. For this case, the crack size is unique.

In conclusion, a robust identification of the crack size and location can be done by considering only the cracked pulsations with the associated factor $\% \Delta_{i}^{\text {cracked }}$ and the three cases: the simply supported beam, the simply supported beam with an added mass at the left end, and the simply supported beam with an added mass at the right end. The location where the three curves intersect for each case is unique and gives the crack size and location.

It may be remained that this damage detection is based on the fact that the system has double frequencies in the undamaged configuration and that the pulsation changes of the bending modes due to the crack are more important in the vertical planes than in the horizontal planes. Moreover, this damage index has been chosen due to the fact that the difference between the pulsation changes in the vertical and horizontal planes only depends on the crack size.

\subsection{Adaptated robust identification technique}

Many studies have been devoted to detect crack in rectangular cross section beams or structures where the pulsations are only measured in one direction. In these cases, the robust identification of crack location and size using the pulsation ratio contour lines method that has been previously presented can be extended.

We propose to consider the factor

$$
\% \Psi_{i, j}^{\text {cracked }}=100 \times\left(\frac{\omega_{i}^{\text {uncracked }}}{\omega_{j}^{\text {uncracked }}}-\frac{\omega_{i}^{\text {cracked }}}{\omega_{j}^{\text {cracked }}}\right)
$$


where $\omega_{i}^{\text {uncracked }}$ and $\omega_{i}^{\text {cracked }}$ correspond to the $i^{\text {th }}$ pulsations of the uncracked and cracked simply supported beams, respectively.

It may be observed that the factor $\% \Psi_{i, j}^{\text {cracked }}$ is a generalisation of $\% \Delta_{i}^{\text {cracked }}$. Effectively, we have

$$
\% \Delta_{i}^{\text {cracked }}=100 \times \frac{\omega_{2 i-1}^{\text {cracked }}-\omega_{2 i}^{\text {cracked }}}{\omega_{2 i-1}^{\text {cracked }}}=100 \times\left(1-\frac{\omega_{2 i}^{\text {cracked }}}{\omega_{2 i-1}^{\text {cracked }}}\right)
$$

where $i$ defines the $i^{\text {th }}$ mode for the simply supported beam. In this case, $\frac{\omega_{i}^{\text {uncracked }}}{\omega_{j}^{\text {uncracked }}}=1$ (in comparison with Equation23) due to the symmetry of the uncracked cross section for the factor $\% \Delta_{i}^{\text {cracked }}$. By considering the classical pulsation for a simply supported uncracked beam (see Appendix A), Equation 23 ca be rewritten

$$
\% \Psi_{2 \alpha-a, 2 \beta-b}^{\text {cracked }}=100 \times\left(\left(\frac{\alpha}{\beta}\right)^{2}-\frac{\omega_{2 \alpha-a}^{\text {cracked }}}{\omega_{2 \beta-b}^{\text {cracked }}}\right)
$$

with $a$ and $b$ are equal to 0 or 1 , and $\alpha \in \aleph^{*}$ and $\beta \in \aleph^{*}$. The associated analytical expressions of $\% \Psi_{3,1}^{\text {cracked }}$, $\% \Psi_{5,1}^{\text {cracked }}, \% \Psi_{7,1}^{\text {cracked }}, \% \Psi_{5,3}^{\text {cracked }}, \% \Psi_{7,3}^{\text {cracked }}$ and $\% \Psi_{7,5}^{\text {cracked }}$ are given in Appendix A. Considering Equation 25, it is clear that the factors $\% \Psi_{2 \alpha-a, 2 \beta-b}^{\text {cracked }}$ need only the knowledge of the pulsations of the simply supported cracked beam and do not change with the variations of the material properties like the Young modulus and the density.

Figures 9 show the variations of these expressions with the non-dimensional crack depth and the crack location. First of all, if $\% \Psi_{i, j}^{\text {cracked }}$ is higher than 0 , it may be concluded that the the mode of $i^{\text {th }}$ pulsation is more affected by the crack than the mode of $j^{\text {th }}$ pulsation. From the results obtained in Figures 9(a), it is observed, for example, that when the crack location is between [ 00.3$]$ or [ 0.71$]$ (for the non-dimensional crack depth $\mu=1$ ), the first pulsation (associated with the first vertical mode) is comparatively much less affected than the third pulsation (associated with the second vertical mode). For a crack situated between [ $\left.\begin{array}{lll}0.3 & 0.7\end{array}\right]$, the scenario is reversed. From the analysis of Figure 9(d), the fifth pulsation (associated to the third vertical mode) is more affected than the the third pulsation (associated to the second vertical mode) if the crack location is situated between [0 0.15], [0.4 0.6] and [0.85 1] (for $\mu=1$ ).

Moreover, if $\% \Psi_{i, j}^{\text {cracked }}$ is lower than 0 , the more affected mode corresponds to the $j^{\text {th }}$ pulsation. For example, Figure 9(f) illustrates the fact that the fifth pulsation (associated with the third vertical mode) is more affected that the seventh pulsation (associated with the fourth vertical mode) for a crack located approximately at [0.12 0.3], [0.45 0.6], and [0.72 0.9] (for $\mu=1$ ).

Secondly, it is noted that the minimum of $\% \Psi_{i, j}^{\text {cracked }}$ results from the fact that the mode of $j^{\text {th }}$ pulsation is almost unaffected for a crack whereas the mode of $i^{\text {th }}$ pulsation is greatly affected. For example, Figures 9(a) shows that the second vertical mode that is associated with the third pulsation is unaffected for a crack located at the center of the simply supported beam that corresponds to the nodal point of the second mode shape. From the results of Figures 9(c) and (f), it can be seen that the fourth vertical mode that corresponds to the seventh pulsation is unaffected for a crack at the center of the beam.

With reference to Figure 9, it can be seen that the factor $\% \Psi_{i, j}^{\text {cracked }}$ and the local associated minima and maxima indicate the trends of changes of the bending moment and its effect on both the mode of $j^{\text {th }}$ pulsation and the mode of $i^{\text {th }}$ pulsation. It reflects one of the well-known effects of cracks on the modal properties of cracked beams (see for example [2]).

All the factors $\% \Psi_{i, j}^{\text {cracked }}$ decrease or increase rapidly with increasing of the non-dimensional crack crack depth $\mu$. Therefore, the detection of lower crack detph appears to be easily done.

Considering Figures 9, it can be concluded that both the crack location and the non-dimensional crack depth have influence on the more affected pulsation of the cracked beam. It appears therefore that the change in the factor $\% \Psi_{i, j}^{\text {cracked }}$ is not only a function of crack depth, and crack location, but also of the pulsation number and the associated mode shape. Then, the damage detection technique that depends on the measured changes in the three factors $\% \Psi_{3,1}^{\text {cracked }}, \% \Psi_{5,1}^{\text {cracked }}$ and $\% \Psi_{7,1}^{\text {cracked }}$ (corresponding to the first, second and third vertical modes of the simply supported beam) is used. Figures 10 show the contour lines of these factors for the six cases that have been previously examined. Table 7 gives the associated values of $\% \Psi_{3,1}^{\text {cracked }}, \% \Psi_{5,1}^{\text {cracked }}$ and $\% \Psi_{7,1}^{\text {cracked }}$ for each case. Even if the crack location coincides 


\begin{tabular}{cccc} 
Case & $\% \Psi_{3,1}^{\text {cracked }}$ & $\% \Psi_{5,1}^{\text {cracked }}$ & $\% \Psi_{7,1}^{\text {cracked }}$ \\
\hline (a) & 0.44 & -1.15 & -2.24 \\
(b) & 19.66 & 17.30 & -50.56 \\
(c) & -14.83 & -2.82 & -56.94 \\
(d) & -3.11 & -1.56 & -9.00 \\
(e) & 12.74 & 29.78 & 12.08 \\
(f) & 5.35 & 13.96 & 7.84 \\
\hline
\end{tabular}

Table 7: Values of $\% \Psi_{i, j}^{\text {cracked }}$ for each case with the simply supported beam

with a vibration node, the contour line of the associated factor do not tend to disappear, and an intersection is obtained. However, the non-uniqueness of the intersection may always induced worse detection of the crack location due to the symmetry of the simply supported beam.

To avoid the the non-uniqueness of the crack identification, the technique using the off-center added mass is applied. The variations of the three factors $\% \Psi_{3,1}^{\text {cracked }}, \% \Psi_{5,1}^{\text {cracked }}$ and $\% \Psi_{7,1}^{\text {cracked }}$ (defined in Equation 25) with a mass that is placed at $L_{\text {mass }}=0.187 \mathrm{~m}$ from the left end of the beam, are shown on Figures 11(a), (c) and (e). It is observed that the factors are not equal to 0 if the beam is uncracked. This is only due to the fact that the location of the added mass influences the pulsations of the simply supported beam. Therefore, the previous ratio $\frac{\omega_{i}^{\text {uncracked }}}{\omega_{j}^{\text {uncracked }}}$ between the $i^{\text {th }}$ and $j^{\text {th }}$ modes of the uncracked beam is not equal to $\frac{i^{2}}{j^{2}}$ any more. Strictly speaking, this last comment is not a problem for the crack identification technique using the factors $\% \Psi_{i, j}^{\text {cracked }}$. For the readers' understanding, these factors may be corrected in order to be equal to 0 for the uncracked beam by considering the following correction $\% \Psi_{i, j}^{\text {corrected }}$ of the factor $\% \Psi_{i, j}^{\text {cracked }}$

$$
\% \Psi_{i, j}^{\text {corrected }}=100 \times\left(\frac{\omega_{i}^{\text {uncracked }}\left(L_{\text {mass }}\right)}{\omega_{j}^{\text {uncracked }}\left(L_{\text {mass }}\right)}-\frac{\omega_{i}^{\text {cracked }}}{\omega_{j}^{\text {cracked }}}\right)
$$

where $\omega_{i}^{\text {uncracked }}\left(L_{\text {mass }}\right)$ defines the $i^{\text {th }}$ uncracked pulsation that is a function of the added mass location. Figures 11(b), (c) and (f) show the corrected factor $\% \Psi_{3,1}^{\text {corrected }}, \% \Psi_{5,1}^{\text {corrected }}$ and $\% \Psi_{7,1}^{\text {corrected }}$, respectively. It is clear that the curves of corrected factor $\% \Psi_{i, j}^{\text {corrected }}$ are only a translatory movement of the curves of $\% \Psi_{i, j}^{\text {cracked }}$. It is significant to note that the ratio $\frac{\omega_{i}^{\text {uncracked }}\left(L_{\text {mass }}\right)}{\omega_{j}^{\text {uncracked }}\left(L_{\text {mass }}\right)}$ is independent of the Young modulus and the density and can be easily obtained numerically without experimental tests.

From the curves given in Figures 11, it is seen that the variations of $\% \Psi_{i, j}^{\text {cracked }}$ and $\% \Psi_{i, j}^{\text {corrected }}$ are similar. Finally, the identification technique of adding an off-center mass at the left side initially, and then at the right side, is used in order to uniquely detect the crack size and location. Figures 12 and 13 show the ratio pulsation contour lines of the factors $\% \Psi_{3,1}^{\text {cracked }}, \% \Psi_{5,1}^{\text {cracked }}$ and $\% \Psi_{7,1}^{\text {cracked }}$ with left and right added masses for the six previous cases. Tables 8 and 9 indicate the corresponding values of $\% \Psi_{i, j}^{\text {cracked }}$ for the three pulsation ratio contour lines. For each case, it appears that only one intersection of the three contour lines is obtained and no confusion may be done. Thereby, it is clear that a robust detection of both the crack size and crack location can be done by considering the three tests: the simply supported beam (see Figures 10), the simply supported beam with a left added mass (see Figures 12), and the simply supported beam with a right added mass (see Figures 10).

It is seen, from the results given in Tables 8 and 9 that the factors $\% \Psi_{i, j}^{\text {corrected }}$ are only a translation of the factors $\% \Psi_{i, j}^{\text {cracked }}$. Moreover, it appears that the variations of $\% \Psi_{i, j}^{\text {cracked }}$ are important and can be utilized to detect crack of small size. 


\begin{tabular}{ccccccc}
\hline & & & & & \\
Case & $\% \Psi_{3,1}^{\text {cracked }}$ & $\% \Psi_{5,1}^{\text {cracked }}$ & $\% \Psi_{7,1}^{\text {cracked }}$ & $\% \Psi_{3,1}^{\text {corrected }}$ & $\% \Psi_{5,1}^{\text {corrected }}$ & $\% \Psi_{7,1}^{\text {corrected }}$ \\
\hline (a) & 39.53 & 72.80 & 176.79 & 0.13 & -1.85 & -0.02 \\
(b) & 53.75 & 103.51 & 149.69 & 14.35 & 28.86 & -27.12 \\
(c) & 27.94 & 66.50 & 142.79 & -11.46 & -8.15 & -34.02 \\
(d) & 37.23 & 71.32 & 172.34 & -2.17 & -3.33 & -4.47 \\
(e) & 48.10 & 105.42 & 189.67 & 8.70 & 30.77 & 12.86 \\
(f) & 47.61 & 82.23 & 163.77 & 8.21 & 7.58 & -13.03 \\
\hline
\end{tabular}

Table 8: Values of $\% \Psi_{i, j}^{\text {cracked }}$ and $\% \Psi_{i, j}^{\text {corrected }}$ for each case with the simply supported beam and the left added mass

\begin{tabular}{ccccccc}
\hline & & & & & \\
Case & $\% \Psi_{3,1}^{\text {cracked }}$ & $\% \Psi_{5,1}^{\text {cracked }}$ & $\% \Psi_{7,1}^{\text {cracked }}$ & $\% \Psi_{3,1}^{\text {corrected }}$ & $\% \Psi_{5,1}^{\text {corrected }}$ & $\% \Psi_{7,1}^{\text {corrected }}$ \\
\hline (a) & 39.77 & 74.28 & 174.44 & 0.37 & -0.37 & -2.37 \\
(b) & 59.03 & 53.99 & 127.93 & 19.63 & -20.66 & -48.88 \\
(c) & 26.69 & 71.00 & 130.89 & -12.71 & -3.65 & -45.92 \\
(d) & 36.38 & 74.31 & 164.90 & -3.02 & -0.34 & -11.90 \\
(e) & 58.04 & 88.64 & 143.67 & 18.64 & 13.99 & -33.14 \\
(f) & 43.00 & 88.54 & 184.18 & 3.60 & 13.89 & 7.37 \\
\hline
\end{tabular}

Table 9: Values of $\% \Psi_{i, j}^{\text {cracked }}$ and $\% \Psi_{i, j}^{\text {corrected }}$ for each case with the simply supported beam and the right added mass

\section{Conclusion}

In this paper we have proposed a new criterion for damage detection and assessment. This criterion considers the ratio pulsation changes of the cracked beam. One of the advantages of the criterion presented here is that the sensitivity of each criterion parameter $\% \Delta_{i}^{\text {cracked }}$ and $\% \Psi_{i, j}^{\text {cracked }}$ do not require an accurate knowledge of the material properties (i.e. the Young modulus and the density). Moreover, the pulsations of the uncracked beam are not used for the identification technique. The damage detection approach was applied to the problem of identifying a crack in a circular cross section beam. To do that, an cracked beam model was formulated based on finite element formulation, and the local stiffness reduction into a crack section.

The predictor of crack size and location is based on the intersection of pulsation ratios contour lines. If the beam has structural symmetry, the identification of crack location is performed by adding an off-center mass in order to avoid worse diagnostic. Based on the results of the analysis and numerical simulations performed, it is concluded that the proposed approach is able to determine the size and location of the crack for beams. The identification method can adapt to a variety of beams without requiring a reformulation. It is believed that this identification technique can be easily applied for experimental detection of crack size as well as crack location. 


\section{Appendix A. Analytical solution of a simply supported uncracked beam and expres- sion of $\% \Psi_{i, j}^{\text {cracked }}$}

The classical $n^{\text {th }}$ pulsation for a simply supported continuous Euler-Bernouilli uncracked beam is defined as

$$
\omega_{n}^{\text {uncracked }}=n^{2} \pi^{2} \sqrt{\frac{E I}{\rho S L^{4}}}
$$

where $n$ are the modes numbers $(n=1,2, \ldots) . L$ is the length of the beam. $E$ and $\rho$ defines the Young modulus and density, and so correspond to the material properties. $I$ and $S$ are the moment of inertia and area of the beam section. For a circular cross section beam, we have

$$
\omega_{n}^{\text {uncracked }}=\frac{n^{2} \pi^{2} R}{2 L^{2}} \sqrt{\frac{E}{\rho}} .
$$

The expressions of $\% \Psi_{3,1}^{\text {cracked }}, \% \Psi_{5,1}^{\text {cracked }}, \% \Psi_{7,1}^{\text {cracked }}, \% \Psi_{5,3}^{\text {cracked }}, \% \Psi_{7,3}^{\text {cracked }}$ and $\% \Psi_{7,5}^{\text {cracked }}$ are given by

$$
\begin{aligned}
& \% \Psi_{3,1}^{\text {cracked }}=100 \times\left(4-\frac{\omega_{3}^{\text {cracked }}}{\omega_{1}^{\text {cracked }}}\right) \\
& \% \Psi_{5,1}^{\text {cracked }}=100 \times\left(9-\frac{\omega_{5}^{\text {cracked }}}{\omega_{1}^{\text {cracked }}}\right) \\
& \% \Psi_{7,1}^{\text {cracked }}=100 \times\left(16-\frac{\omega_{7}^{\text {cracked }}}{\omega_{1}^{\text {cracked }}}\right) \\
& \% \Psi_{5,3}^{\text {cracked }}=100 \times\left(\frac{9}{4}-\frac{\omega_{5}^{\text {cracked }}}{\omega_{3}^{\text {cracked }}}\right) \\
& \% \Psi_{7,3}^{\text {cracked }}=100 \times\left(4-\frac{\omega_{7}^{\text {cracked }}}{\omega_{3}^{\text {cracked }}}\right) \\
& \% \Psi_{7,5}^{\text {cracked }}=100 \times\left(\frac{16}{9}-\frac{\omega_{7}^{\text {cracked }}}{\omega_{5}^{\text {cracked }}}\right)
\end{aligned}
$$




\section{References}

[1] Adams, R., Cawley, P., Pye, C., and Stone, B., 1978. "A vibration technique for non-destructively assessing the integrity of structures". Journal of Mechanical Engineering Science, 20, pp. 93-100.

[2] Morassi, A., 1993. "Crack-induced changes in eigenparameters of beam structures". American Society of Civil Engineers, Journal of Engineering Mechanics, 119, pp. 1798-1803.

[3] Hearn, G., and Testa, R., 1991. "Modal analysis for damage detection in structures". American Society of Civil Engineers, Journal of Structural Engineering, 117, pp. 3042-3063.

[4] Liang, R., Hu, J., and Choy, F., 1992. "Theoretical study of crack-induced eigenfrequency changes on beam structures". American Society of Civil Engineers, Journal of Engineering Mechanics, 118(2), pp. 384-396.

[5] Narkis, Y., 1994. "Identification of crack location in vibrating simply supported beams". Journal of Sound and Vibration, 172(4), pp. 549-558.

[6] Morassi, A., 2001. "Identification of a crack on a rod based on changes in a pair of natural frequencies". Journal of Sound and Vibration, 242(4), pp. 577-596.

[7] Dilena, M., and Morassi, A., 2002. "Identification of crack location in vibrating beams from changes in node positions". Journal of Sound and Vibration, 255(5), pp. 915-930.

[8] Gladwell, G., and Morassi, A., 1999. "Estimating damage in a rod from changes in node positions". Inverse Problems in Engineering, 7, pp. 215-233.

[9] Dilena, M., and Morassi, A., 2004. "The use of antiresonances for crack detection in beams". Journal of Sound and Vibration, 276, pp. 195--214.

[10] Liang, R., Choy, F., and Hu, J., 1991. "Detection of cracks in beam structures using measurements of natural frequencies". Journal of the Franklin Institute, 328(4), pp. 505-518.

[11] Cerri, M. N., and Vestroni, F., 2000. "Detection of damage in beams subjected to diffused cracking". Journal of Sound and Vibration, 234(2), pp. 259-276.

[12] Owolabi, G., Swamidas, A., and Seshadri, R., 2003. "Crack detection in beams using changes in frequencies and amplitudes of frequency response functions". Journal of Sound and Vibration, 265, pp. 1-22.

[13] Nahvi, H., and Jabbari, M., 2005. "Crack detection in beams using experimental modal data and finite element model”. International Journal of Mechanical Sciences, 47, pp. 1477-1497.

[14] Li, B., Chen, X., Ma, J., and He, Z., 2005. "Detection of crack location and size in structures using wavelet finite element methods". Journal of Sound and Vibration, 285, pp. 767—-782.

[15] Hadjileontiadis, L., Doukab, E., and Trochidisc, A., 2005. "Fractal dimension analysis for crack identification in beam structures". Mechanical Systems and Signal Processing, 19, pp. 659-674.

[16] Khiem, N., and Lien, T., 2004. "Multi-crack detection for beam bythe natural frequencies". Journal of Sound and Vibration, 273, pp. 175--184.

[17] Kim, J.-T., and Stubbs, N., 2003. "Crack detection in beam-type structures using frequency data". Journal of Sound and Vibration, 259(1), pp. 145-160.

[18] Nelson, H., and Nataraj, C., 1986. "The dynamics of a rotor system with a cracked shaft". Journal of Vibration, Acoustics, Stress and Reliability in Design, 108, pp. 189-196.

[19] Lalanne, M., and Ferraris, G., 1990. Rotordynamics-Prediction in Engineering. John Wiley and Sons. 
[20] Dimarogonas, A., 1996. "Vibration of cracked structures: a state of the art review". Applied Mechanics Review, 55, pp. 831-857.

[21] Wauer, J., 1990. "Dynamics of cracked rotors: Literature survey”. Applied Mechanics Review, 43, pp. $13-17$.

[22] Davies, W. G. R., and Mayes, I. W., 1984. "The vibrational behaviour of a multi-shaft, multi-bearing system in the presence of a propagating transverse crack". Transactions of the ASME Journal of Vibration, Acoustics, Stress, and Reliability in Design, 106, pp. 146-153.

[23] Mayes, I. W., and Davies, W. G. R., 1984. "Analysis of the response of a multi-rotor-bearing system containing a transverse crack in a rotor". Transactions of the ASME Journal of Vibration, Acoustics, Stress, and Reliability in Design, 106, pp. 139-145.

[24] Mayes, I. W., and Davies, W. G. R., 1976. "The vibrational behaviour of a rotating shaft system containing a transverse crack". IMechE Conference on Vibrations in Rotating Machinery, Cambridge, United Kingdom, 1, pp. 53-64.

[25] Lees, A. W., and Friswell, M. I., 2001. "The vibration signature of chordal cracks in asymmetric rotors". Proc. of 19th International Modal Analysis Conference, 1, pp. 1-6.

[26] Sinou, J.-J., and Lees, A. W., 2005. "Influence of cracks in rotating shafts". Journal of Sound and Vibration, 285(4-5), pp. 1015-1037.

[27] Lele, S., and Maiti, S., 2002. "Modeling of transverse vibration of short beams for crack detection and measurement of crack extension". Journal of Sound and Vibration, 257 (3), pp. 559--583.

[28] Swamidas, A., Yang, X., and Seshadri, R., 2004. "Identification of cracking in beam structures using Timoshenko and Euler formulations". Journal of Engineering Mechanics, 130(11), pp. 1297-1308. 

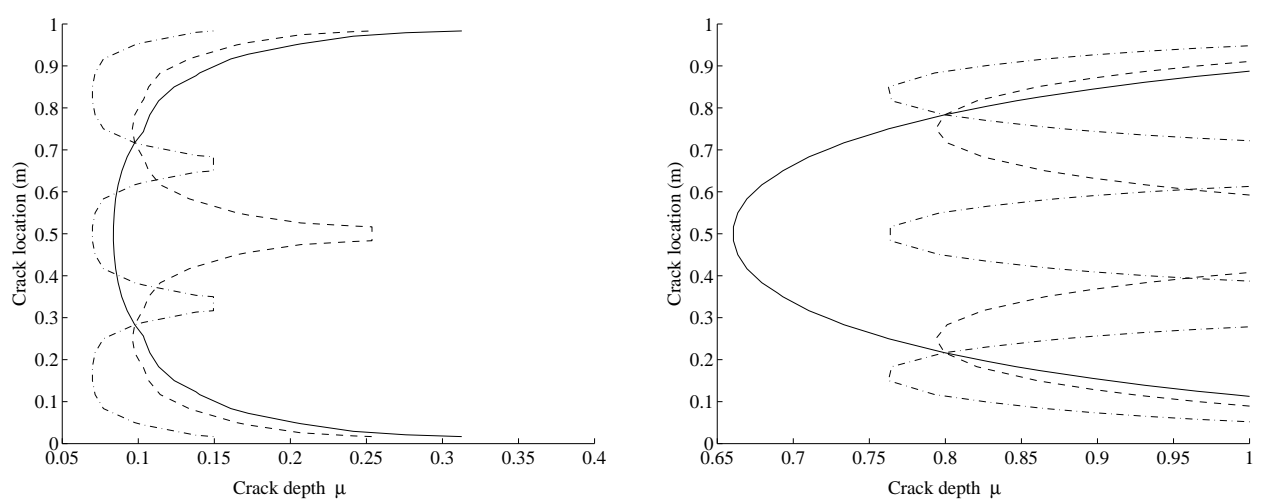

(a) $\mu=0.1$ and $L_{\text {crack }}=0.283 \mathrm{~m}$

(b) $\mu=0.8$ and $L_{\text {crack }}=0.783 \mathrm{~m}$
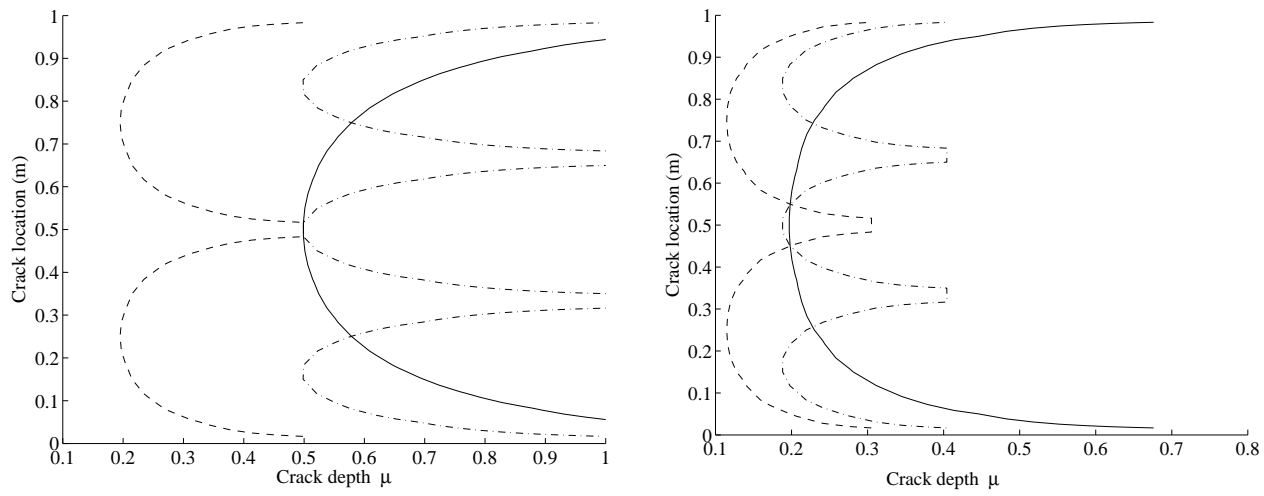

(c) $\mu=0.5$ and $L_{\text {crack }}=0.517 \mathrm{~m}$

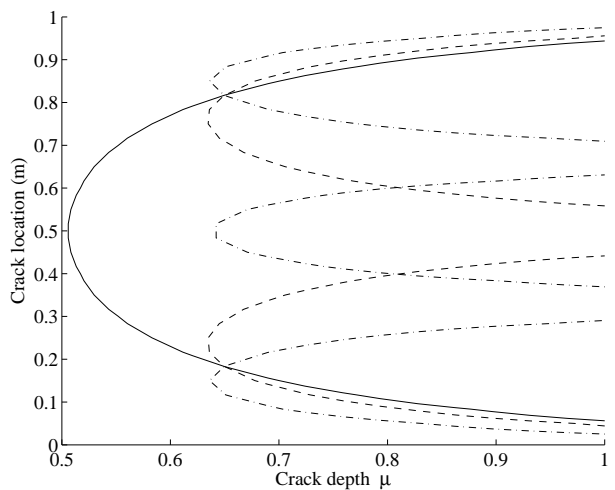

(d) $\mu=0.2$ and $L_{\text {crack }}=0.55 \mathrm{~m}$

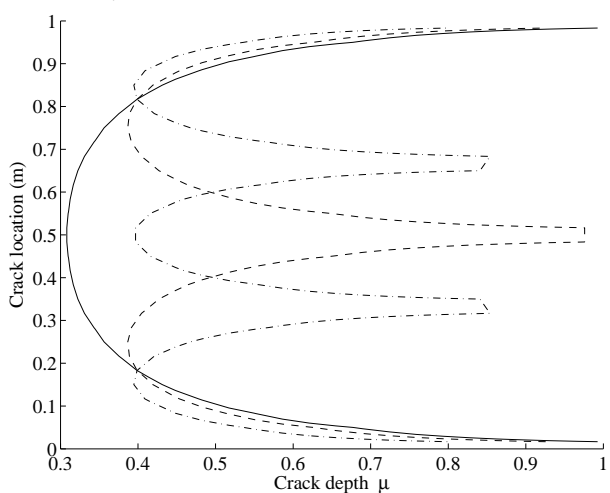

(e) $\mu=0.65$ and $L_{\text {crack }}=0.817 \mathrm{~m}$

(f) $\mu=0.4$ and $L_{\text {crack }}=0.183 \mathrm{~m}$

Figure 4: Identification results with the criterion $\% \Delta_{i}^{\text {cracked }}$ by using the contour lines of the first three frequency ratios for a simply supported beam $\left(-\% \Delta_{1}^{\text {cracked }},--\% \Delta_{2}^{\text {cracked }},-\cdot-\% \Delta_{3}^{\text {cracked }}\right)$ 


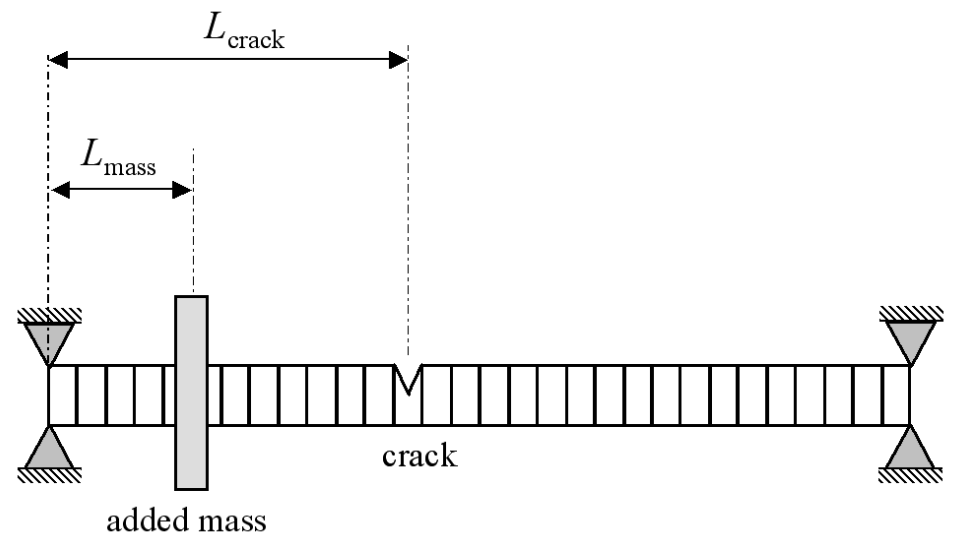

Figure 5: Finite-element model of the beam with the added mass

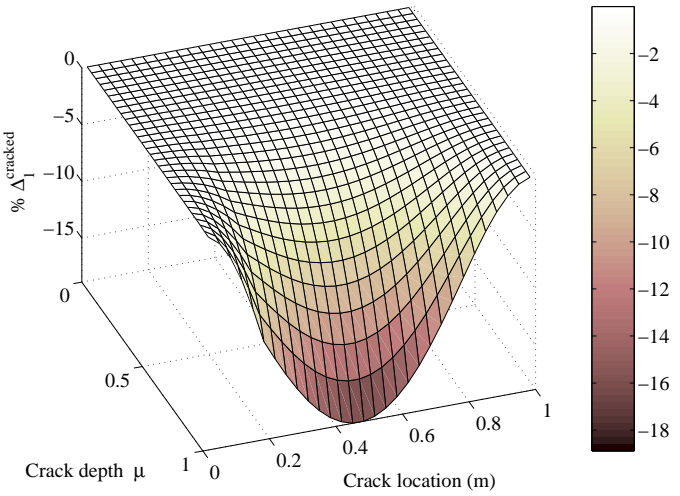

(a) $\% \Delta_{1}^{\text {cracked }}$

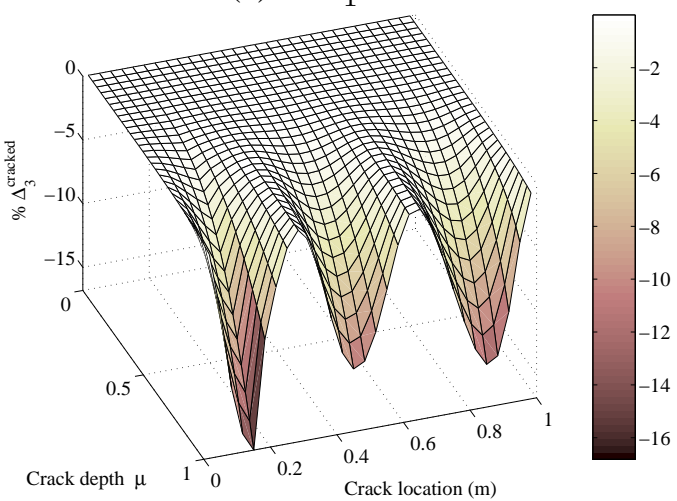

(c) $\% \Delta_{3}^{\text {cracked }}$

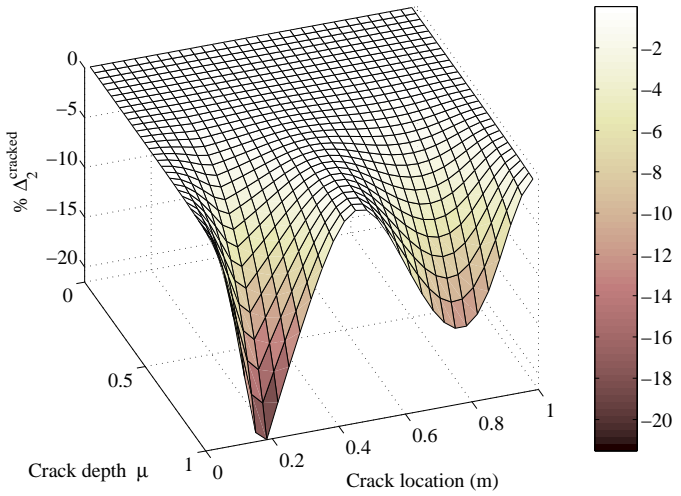

(b) $\% \Delta_{2}^{\text {cracked }}$

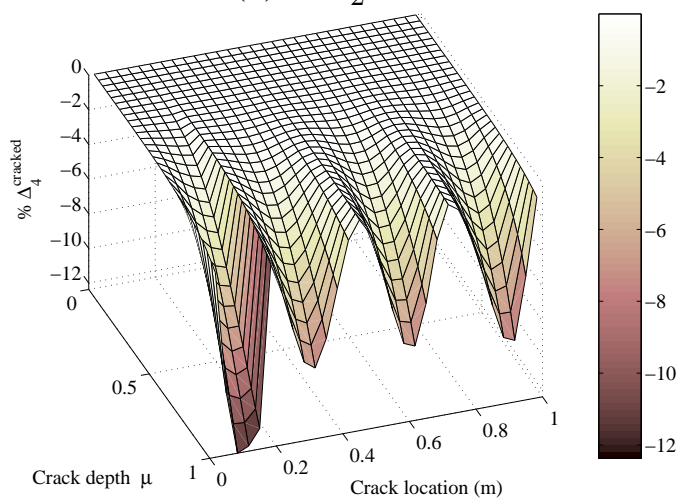

(d) $\% \Delta_{4}^{\text {cracked }}$

Figure 6: Evolution of $\% \Delta_{i}^{\text {cracked }}$ of the beam with an added mass at $L_{\text {mass }}=0.167 \mathrm{~m}$ as a function of the nondimensional crack depth $\mu$ and the crack location $L_{\text {crack }}\left(-\% \Delta_{1}^{\text {cracked }},--\% \Delta_{2}^{\text {cracked }},-\cdot-\% \Delta_{3}^{\text {cracked }}\right)$ 


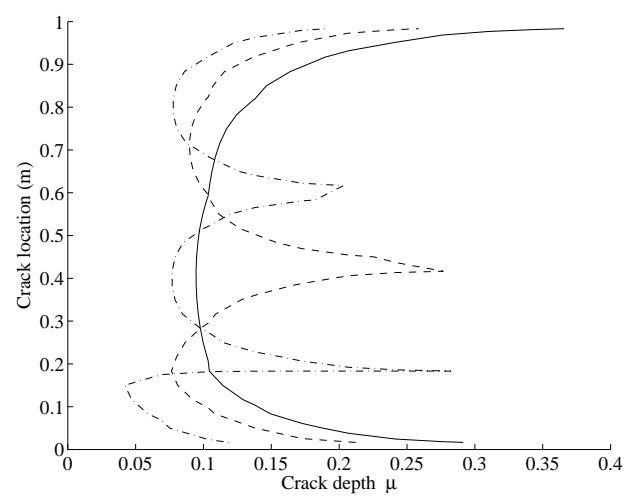

(a) $\mu=0.1$ and $L_{\text {crack }}=0.283 \mathrm{~m}$

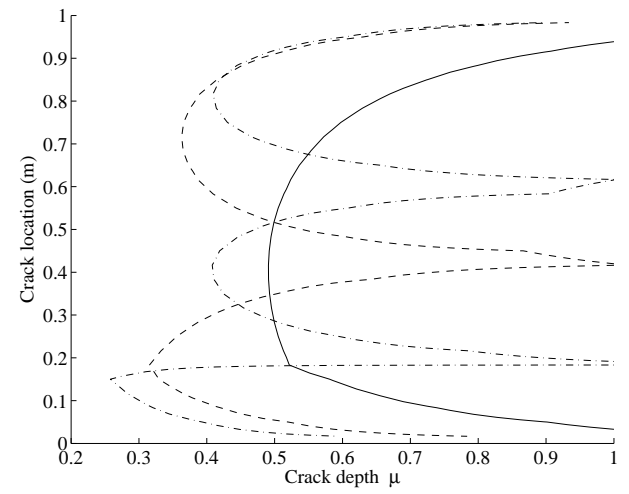

(c) $\mu=0.5$ and $L_{\text {crack }}=0.517 m$

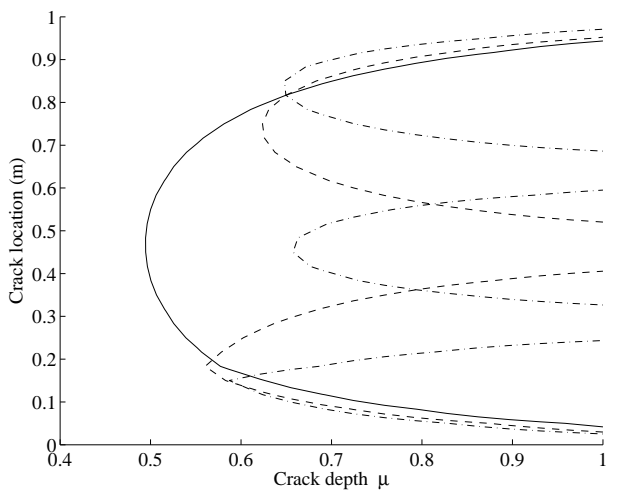

(e) $\mu=0.65$ and $L_{\text {crack }}=0.817 \mathrm{~m}$

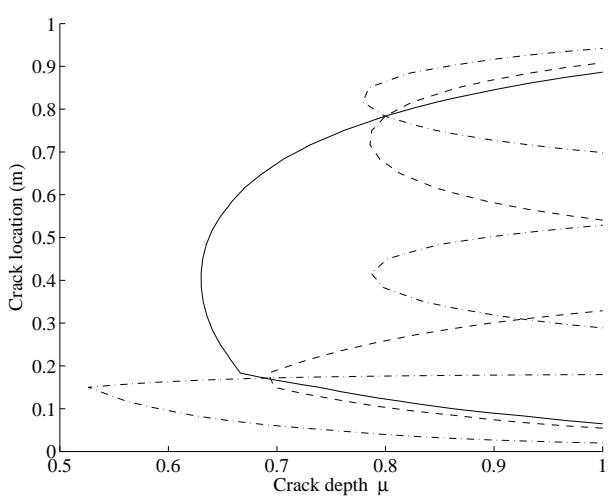

(b) $\mu=0.8$ and $L_{\text {crack }}=0.783 \mathrm{~m}$

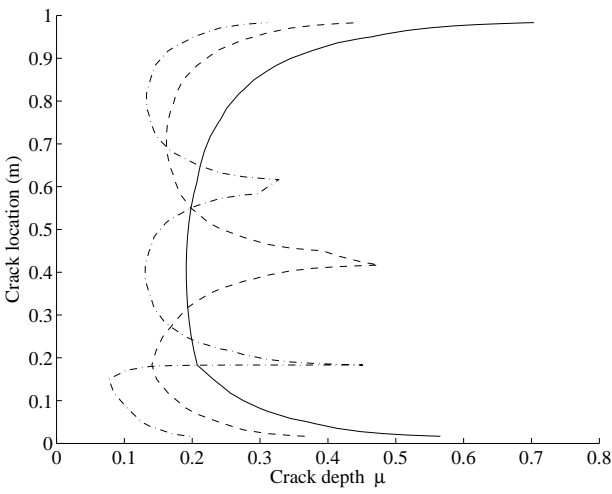

(d) $\mu=0.2$ and $L_{\text {crack }}=0.55 \mathrm{~m}$

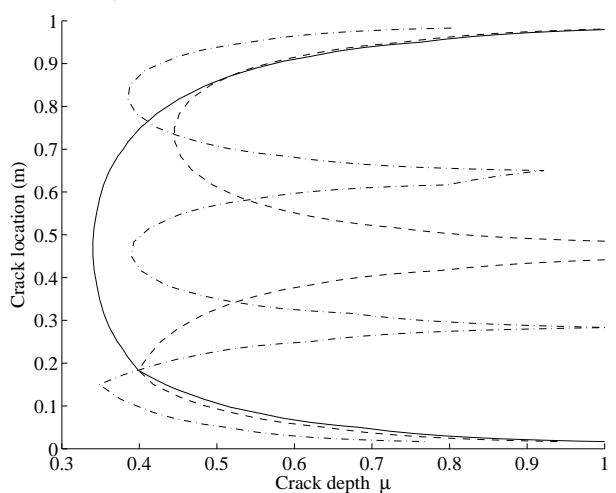

(f) $\mu=0.4$ and $L_{\text {crack }}=0.183 \mathrm{~m}$

Figure 7: Identification results with the criterion $\% \Delta_{i}^{\text {cracked }}$ by using the contour lines of the first three frequency ratios for a simply supported beam with added mass at the left end $L_{\text {mass }}=0.167 m\left(-\% \Delta_{1}^{\text {cracked }},--\% \Delta_{2}^{\text {cracked }}\right.$, $\left.-\cdot-\% \Delta_{3}^{\text {cracked }}\right)$ 


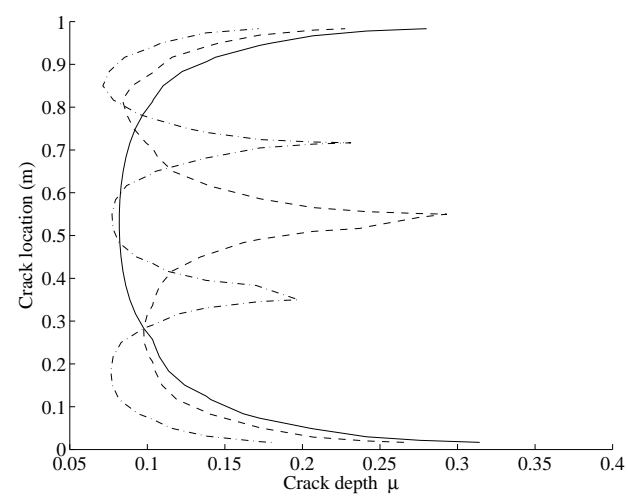

(a) $\mu=0.1$ and $L_{\text {crack }}=0.283 \mathrm{~m}$

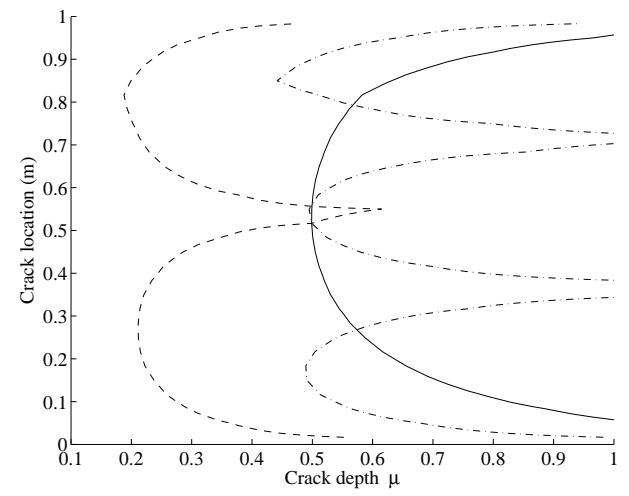

(c) $\mu=0.5$ and $L_{\text {crack }}=0.517 \mathrm{~m}$

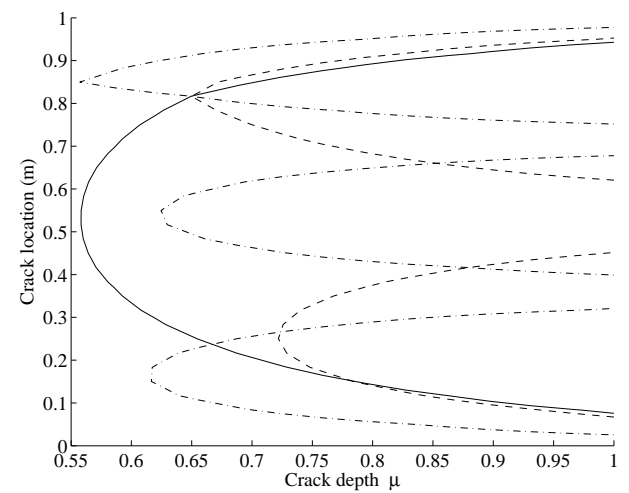

(e) $\mu=0.65$ and $L_{\text {crack }}=0.817 \mathrm{~m}$

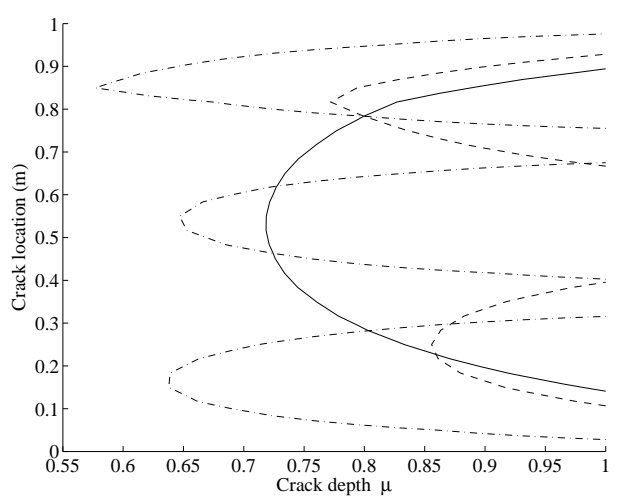

(b) $\mu=0.8$ and $L_{\text {crack }}=0.783 \mathrm{~m}$

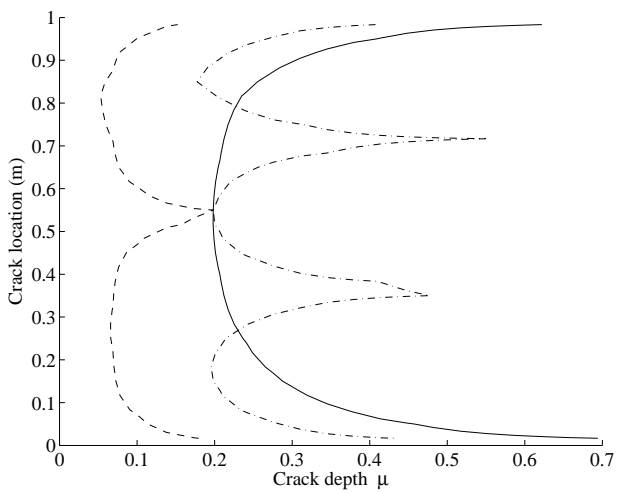

(d) $\mu=0.2$ and $L_{\text {crack }}=0.55 \mathrm{~m}$

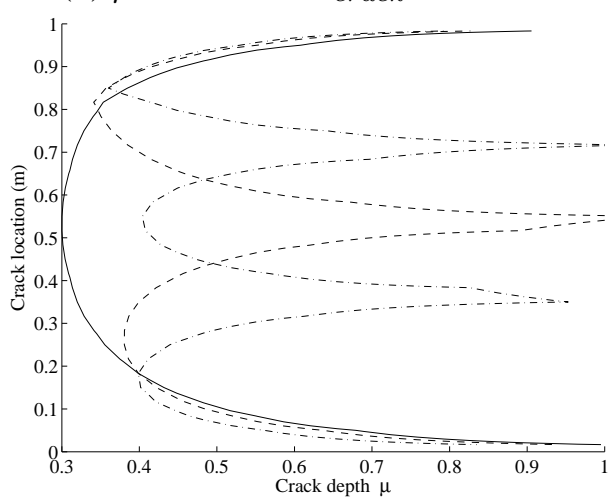

(f) $\mu=0.4$ and $L_{\text {crack }}=0.183 \mathrm{~m}$

Figure 8: Identification results with the criterion $\% \Delta_{i}^{\text {cracked }}$ by using the contour lines of the first three frequency ratios for a simply supported beam with added mass at the right end $L_{\text {mass }}=0.833 m\left(-\% \Delta_{1}^{\text {cracked }},--\% \Delta_{2}^{\text {cracked }},-\cdot-\right.$ $\% \Delta_{3}^{\text {cracked }}$ ) 


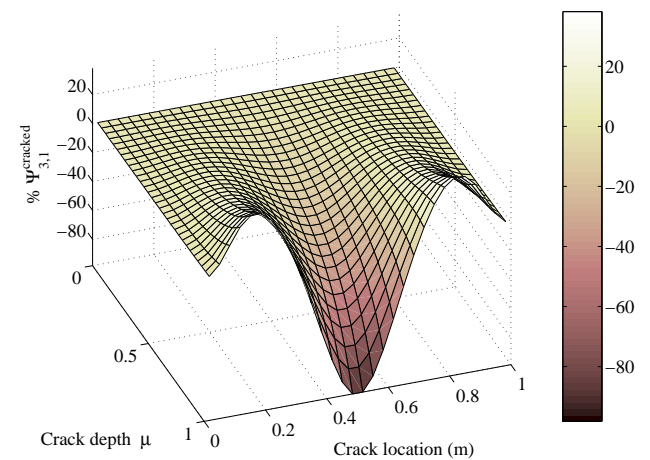

(a) $\% \Psi_{3,1}^{\text {cracked }}$

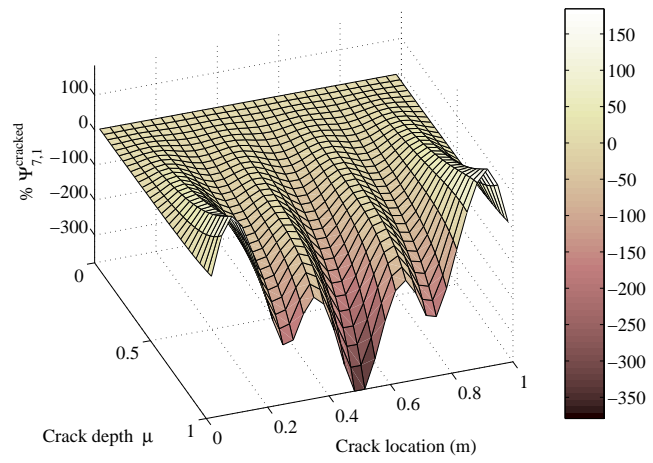

(c) $\% \Psi_{7,1}^{\text {cracked }}$

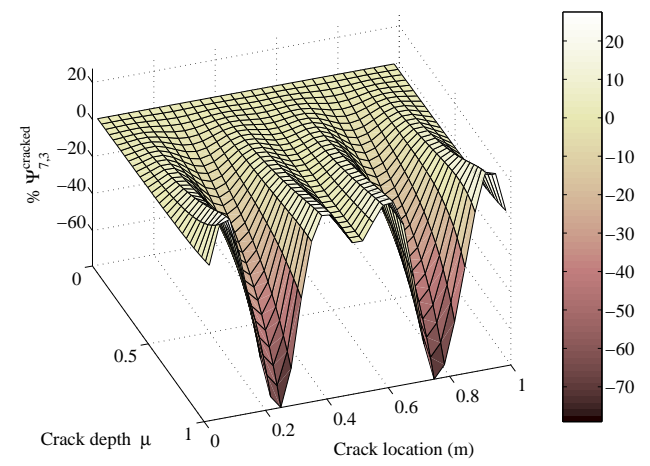

(e) $\% \Psi_{7,3}^{\text {cracked }}$

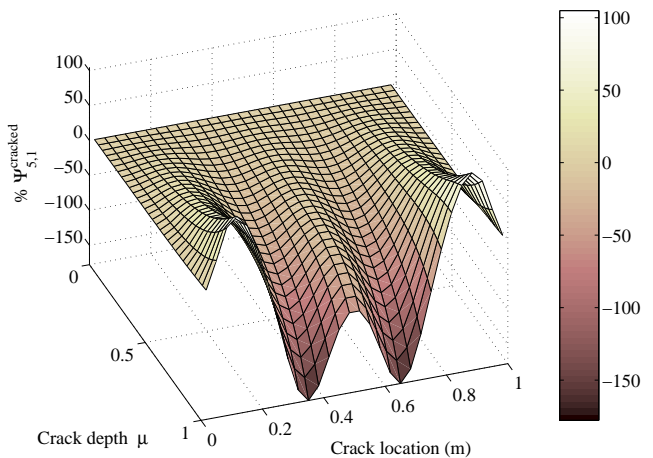

(b) $\% \Psi_{5,1}^{\text {cracked }}$

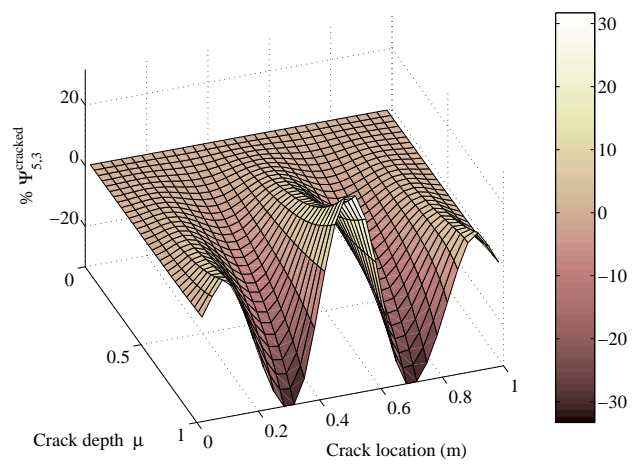

(d) $\% \Psi_{5,3}^{\text {cracked }}$

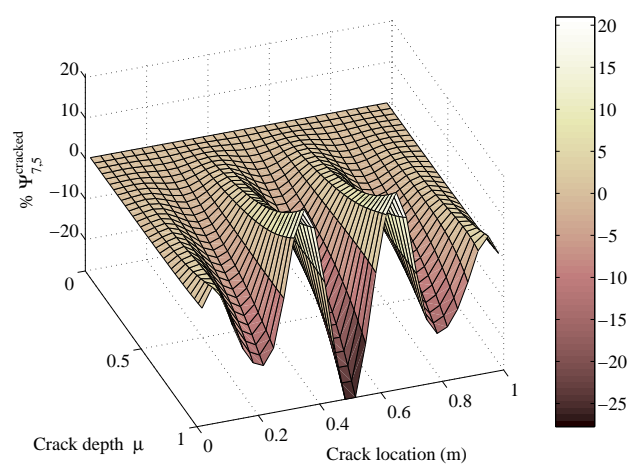

(f) $\% \Psi_{7,5}^{\text {cracked }}$

Figure 9: Evolution of $\% \Psi_{i, j}^{\text {cracked }}$ of the beam as a function of the non-dimensional crack depth $\mu$ and the crack location $L_{\text {crack }}$ 

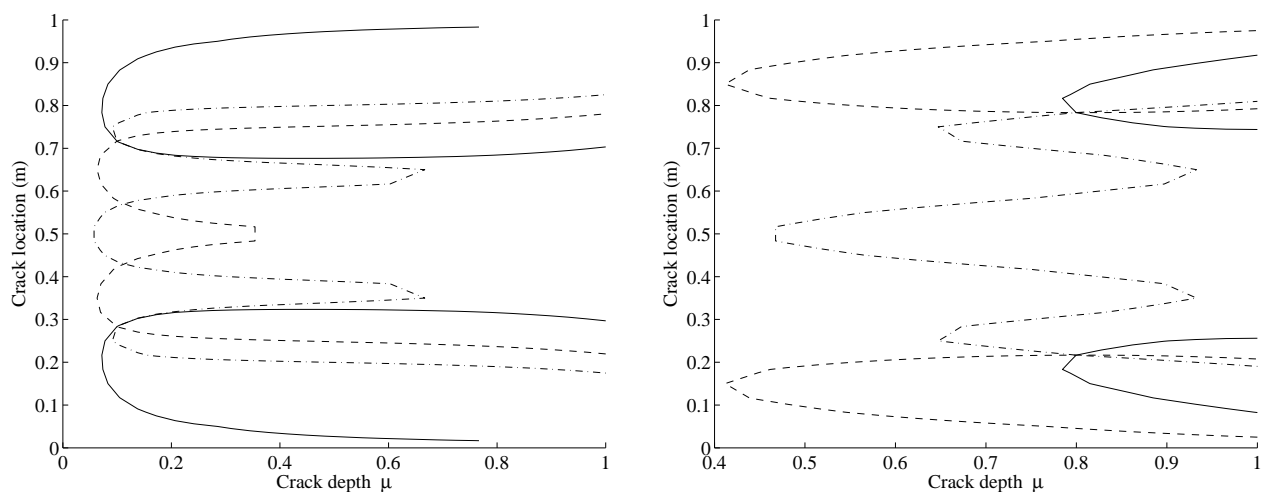

(a) $\mu=0.1$ and $L_{\text {crack }}=0.283 \mathrm{~m}$

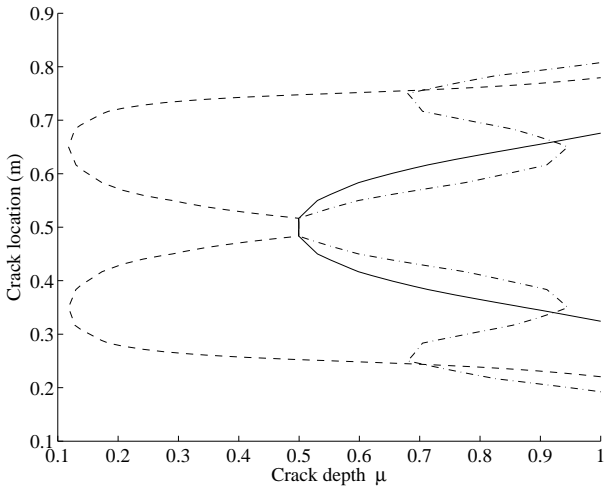

(b) $\mu=0.8$ and $L_{\text {crack }}=0.783 \mathrm{~m}$

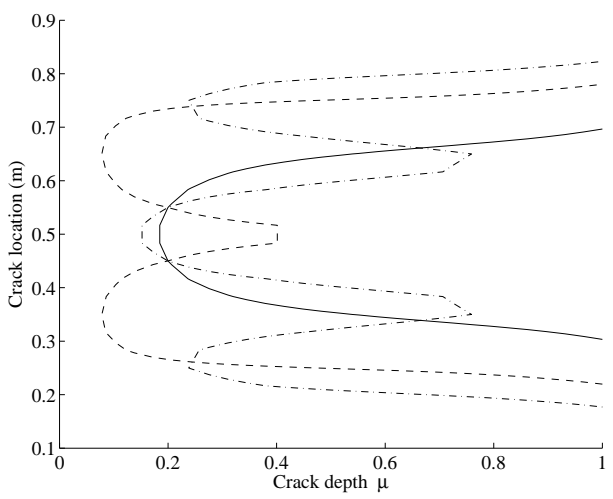

(c) $\mu=0.5$ and $L_{\text {crack }}=0.517 \mathrm{~m}$

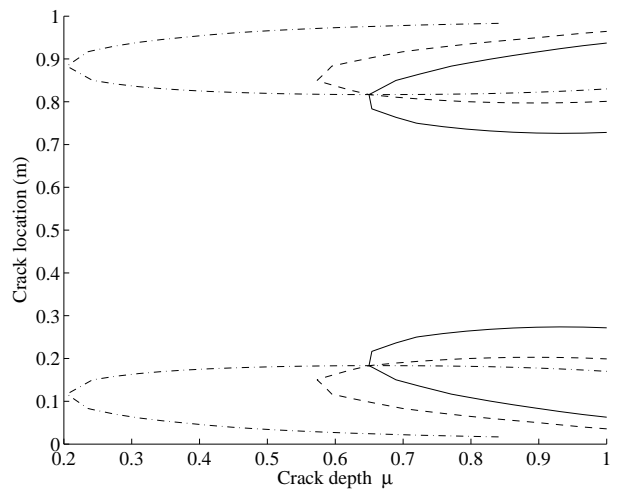

(d) $\mu=0.2$ and $L_{\text {crack }}=0.55 \mathrm{~m}$

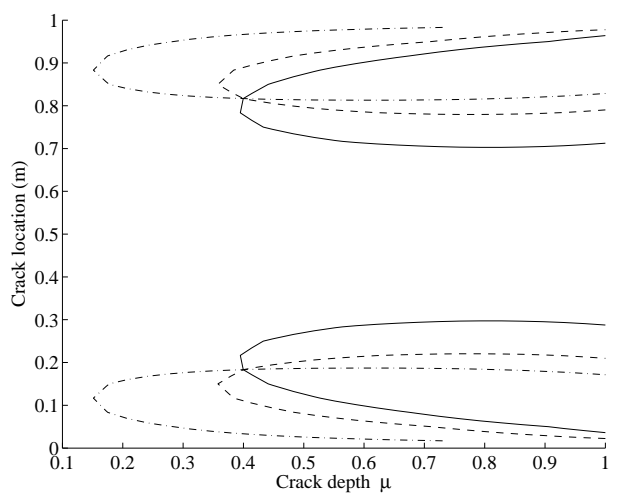

(e) $\mu=0.65$ and $L_{\text {crack }}=0.817 \mathrm{~m}$

(f) $\mu=0.4$ and $L_{\text {crack }}=0.183 \mathrm{~m}$

Figure 10: Identification of crack size and location with $\% \Psi_{i, j}^{\text {cracked }}$ for a simply supported beam ( $-\% \Psi_{3,1}^{\text {cracked }},--$ $\% \Psi_{5,1}^{\text {cracked }},-\cdot-\% \Psi_{7,1}^{\text {cracked }}$ ) 


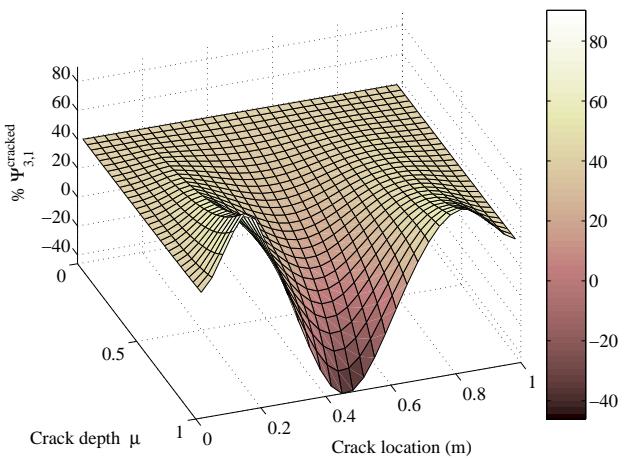

(a) $\% \Psi_{3,1}^{\text {cracked }}$

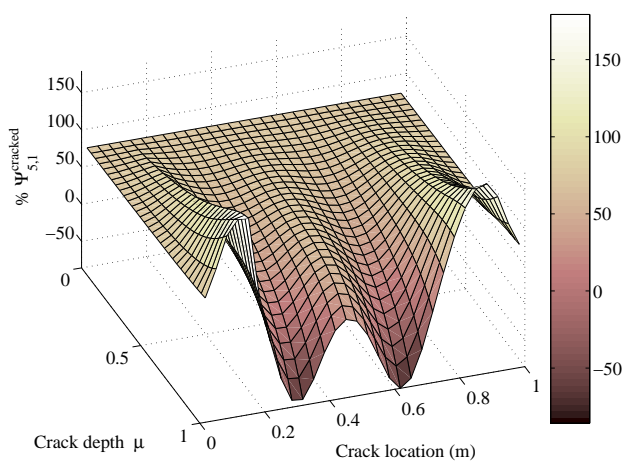

(c) $\% \Psi_{5,1}^{\text {cracked }}$

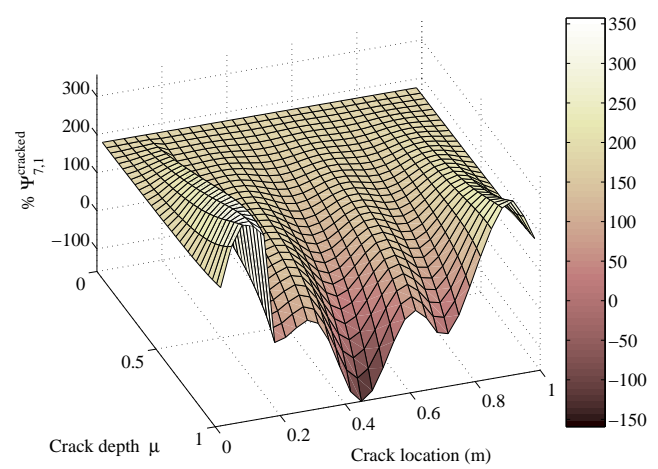

(e) $\% \Psi_{7,1}^{\text {cracked }}$

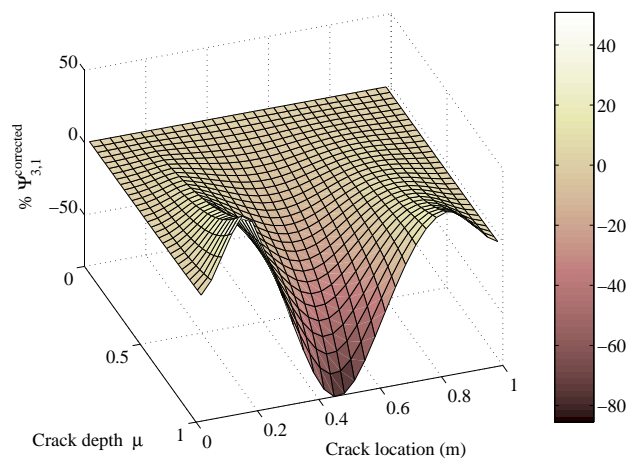

(b) $\% \Psi_{3,1}^{\text {corrected }}$

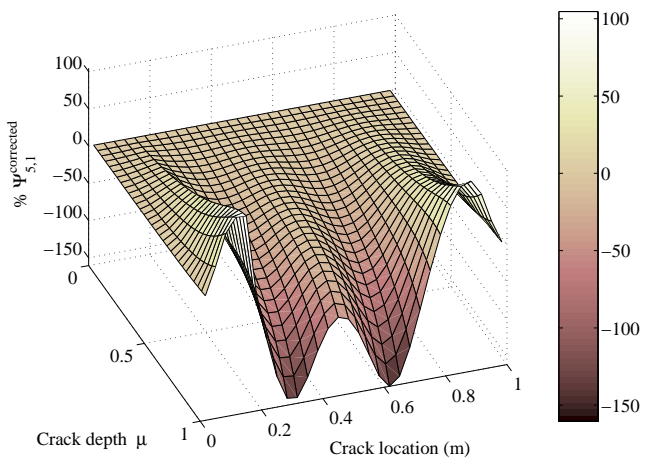

(d) $\% \Psi_{5,1}^{\text {corrected }}$

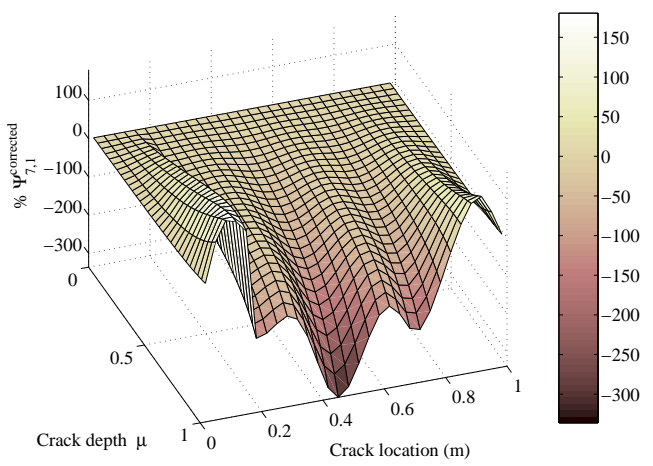

(f) $\% \Psi_{7,1}^{\text {corrected }}$

Figure 11: Evolution of $\% \Psi_{i, j}^{\text {cracked }}$ and the $\% \Psi_{i, j}^{\text {corrected }}$ of the beam with an added mass at $L_{\text {mass }}=0.167 \mathrm{~m}$ as a function of the non-dimensional crack depth $\mu$ and the crack location $L_{\text {crack }}$ 

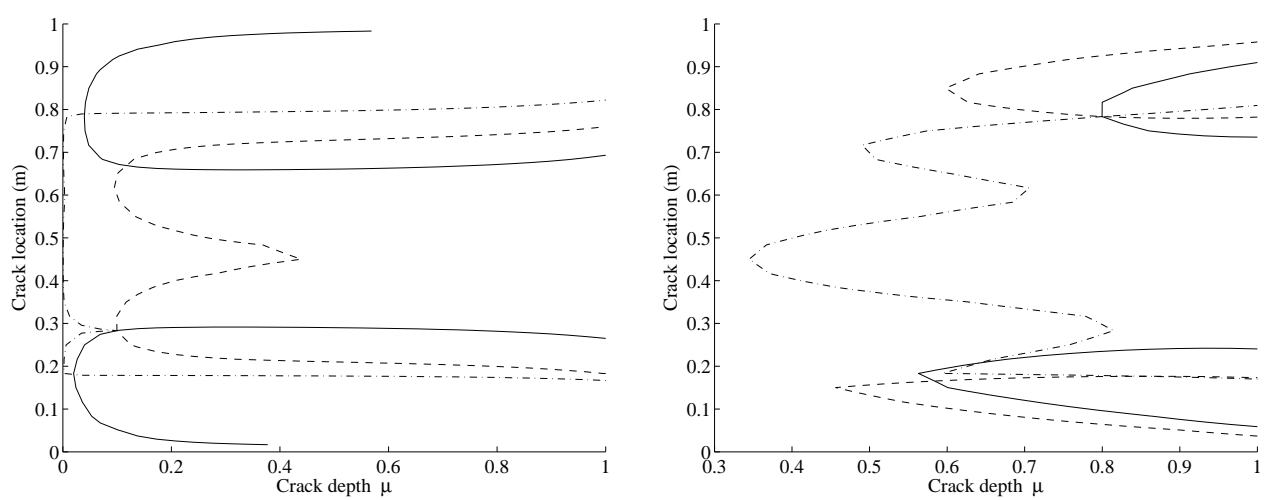

(a) $\mu=0.1$ and $L_{\text {crack }}=0.283 \mathrm{~m}$

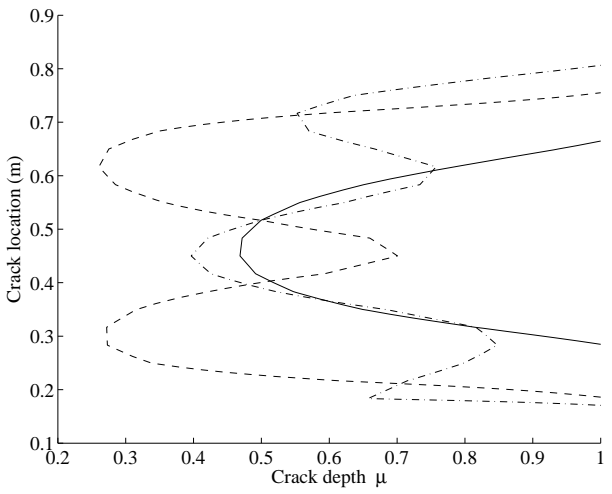

(b) $\mu=0.8$ and $L_{\text {crack }}=0.783 \mathrm{~m}$

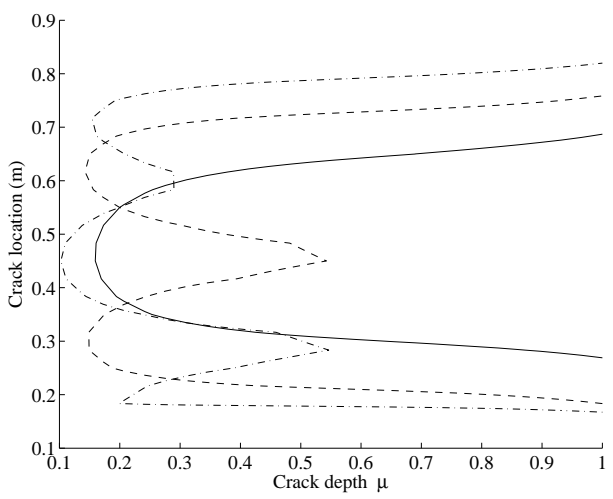

(c) $\mu=0.5$ and $L_{\text {crack }}=0.517 \mathrm{~m}$

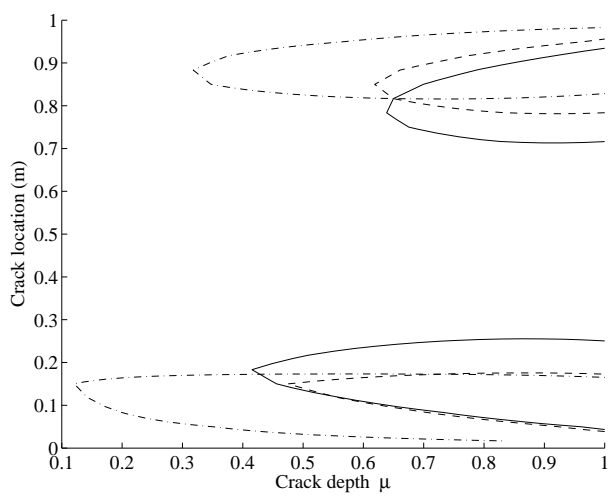

(d) $\mu=0.2$ and $L_{\text {crack }}=0.55 \mathrm{~m}$

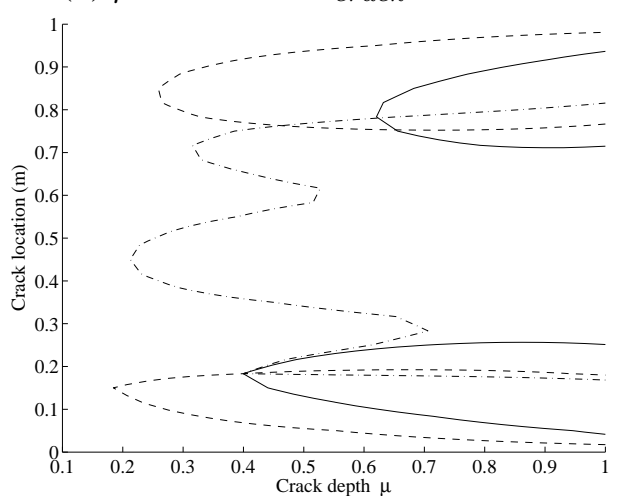

(e) $\mu=0.65$ and $L_{\text {crack }}=0.817 \mathrm{~m}$

(f) $\mu=0.4$ and $L_{\text {crack }}=0.183 \mathrm{~m}$

Figure 12: Identification of crack size and location with $\% \Psi_{i, j}^{\text {cracked }}$ for a simply supported beam with added mass at the left end $L_{\text {mass }}=0.167 m\left(-\% \Psi_{3,1}^{\text {cracked }},--\% \Psi_{5,1}^{\text {cracked }},-\cdot-\% \Psi_{7,1}^{\text {cracked }}\right)$ 

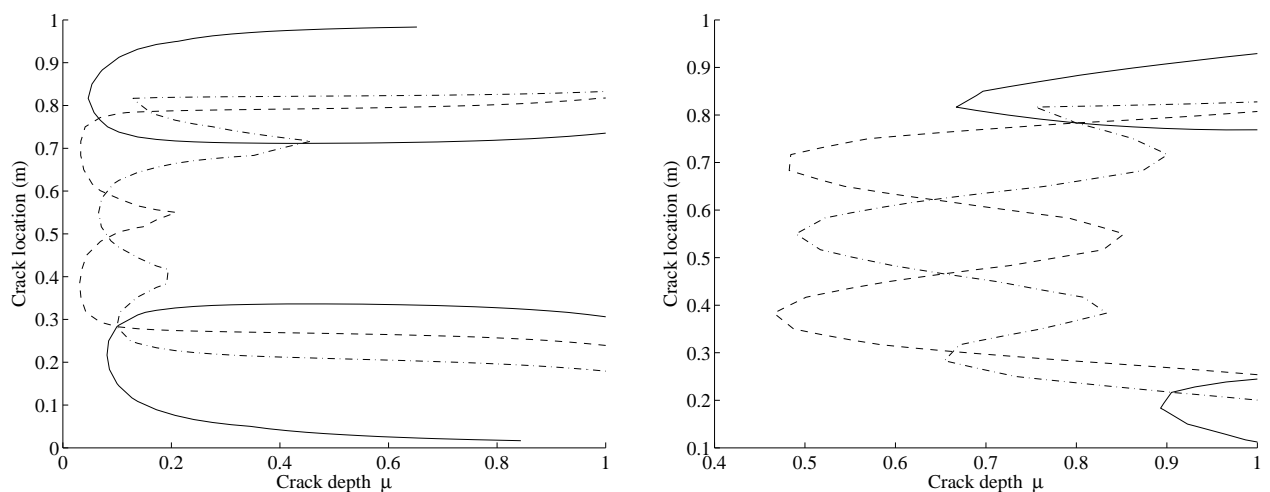

(a) $\mu=0.1$ and $L_{\text {crack }}=0.283 \mathrm{~m}$

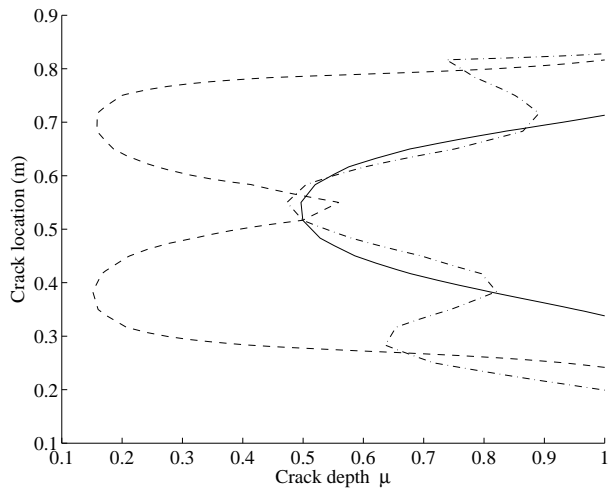

(b) $\mu=0.8$ and $L_{\text {crack }}=0.783 \mathrm{~m}$

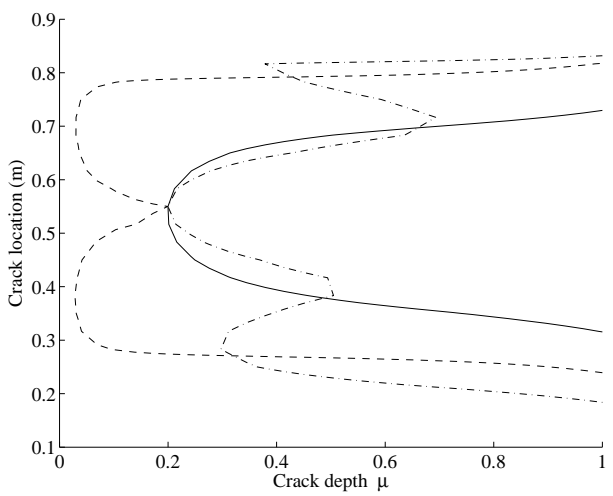

(c) $\mu=0.5$ and $L_{\text {crack }}=0.517 \mathrm{~m}$

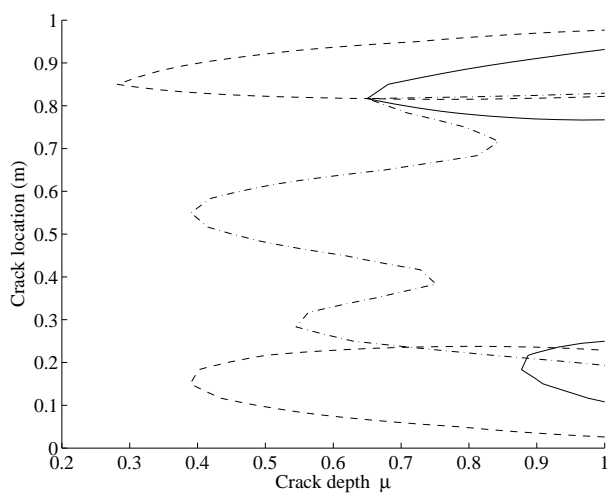

(d) $\mu=0.2$ and $L_{\text {crack }}=0.55 \mathrm{~m}$

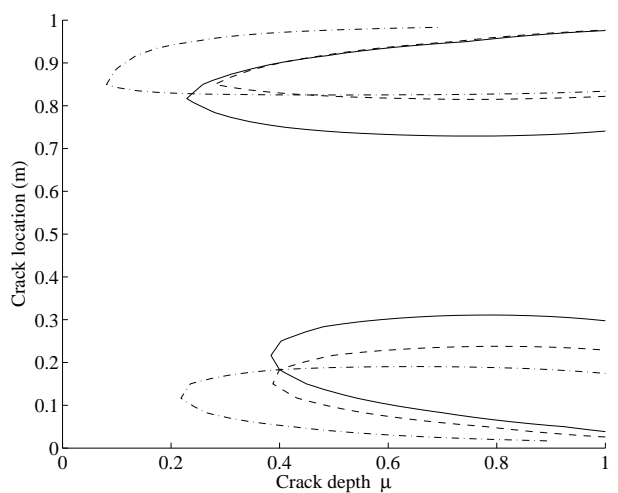

(e) $\mu=0.65$ and $L_{\text {crack }}=0.817 \mathrm{~m}$

(f) $\mu=0.4$ and $L_{\text {crack }}=0.183 \mathrm{~m}$

Figure 13: Identification of crack size and location with $\% \Psi_{i, j}^{\text {cracked }}$ for a simply supported beam with added mass at the right end $L_{\text {mass }}=0.833 m\left(-\% \Psi_{3,1}^{\text {cracked }},--\% \Psi_{5,1}^{\text {cracked }},-\cdot-\% \Psi_{7,1}^{\text {cracked }}\right)$ 